\title{
The Lancet \\ Ethnicity and outcomes from COVID-19: the ISARIC CCP-UK prospective observational cohort study of hospitalised patients \\ --Manuscript Draft--
}

\begin{tabular}{|c|c|}
\hline Manuscript Number: & THELANCET-D-20-12331 \\
\hline Article Type: & FT to NT Article (INTERNAL USE ONLY) \\
\hline \multicolumn{2}{|l|}{ Keywords: } \\
\hline Corresponding Author: & $\begin{array}{l}\text { Ewen M Harrison, MB ChB, MSc, FRCS, PhD } \\
\text { University of Edinburgh } \\
\text { Edinburgh, UNITED KINGDOM }\end{array}$ \\
\hline First Author: & Ewen M Harrison, MB ChB, MSc, FRCS, PhD \\
\hline \multirow[t]{29}{*}{ Order of Authors: } & Ewen M Harrison, MB ChB, MSc, FRCS, PhD \\
\hline & Annemarie B Docherty \\
\hline & Benjamin Barr \\
\hline & Iain Buchan \\
\hline & Gail Carson \\
\hline & Tom M Drake \\
\hline & Jake Dunning \\
\hline & Cameron J Fairfield \\
\hline & Carrol Gamble \\
\hline & Christopher A Green \\
\hline & Chris Griffiths \\
\hline & Sophie Halpin \\
\hline & Hayley E Hardwick \\
\hline & Antonia Ho \\
\hline & Karl A Holden \\
\hline & Joe Hollinghurst \\
\hline & Peter W Horby \\
\hline & Clare Jackson \\
\hline & S Vittal Katikireddi \\
\hline & Stephen Knight \\
\hline & Ronan Lyons \\
\hline & James MacMahon \\
\hline & Kenneth A Mclean \\
\hline & Laura Merson \\
\hline & Derek Murphy \\
\hline & Jonathan S Nguyen-Van-Tam \\
\hline & Lisa Norman \\
\hline & Piero L Olliaro \\
\hline & Manish Pareek \\
\hline
\end{tabular}




\begin{tabular}{|c|c|}
\hline & Roberta Piroddi \\
\hline & Riinu Pius \\
\hline & Jonathan M Read \\
\hline & Clark D Russell \\
\hline & Naveed Sattar \\
\hline & Catherine A Shaw \\
\hline & Aziz Sheikh \\
\hline & Ian P. Sinha \\
\hline & Olivia Swann \\
\hline & David Taylor-Robinson \\
\hline & Daniel Thomas \\
\hline & Lance Turtle \\
\hline & Peter JM Openshaw \\
\hline & J Kenneth Baillie \\
\hline & Malcolm G Semple \\
\hline Manuscript Region of Origin: & UNITED KINGDOM \\
\hline Abstract: & 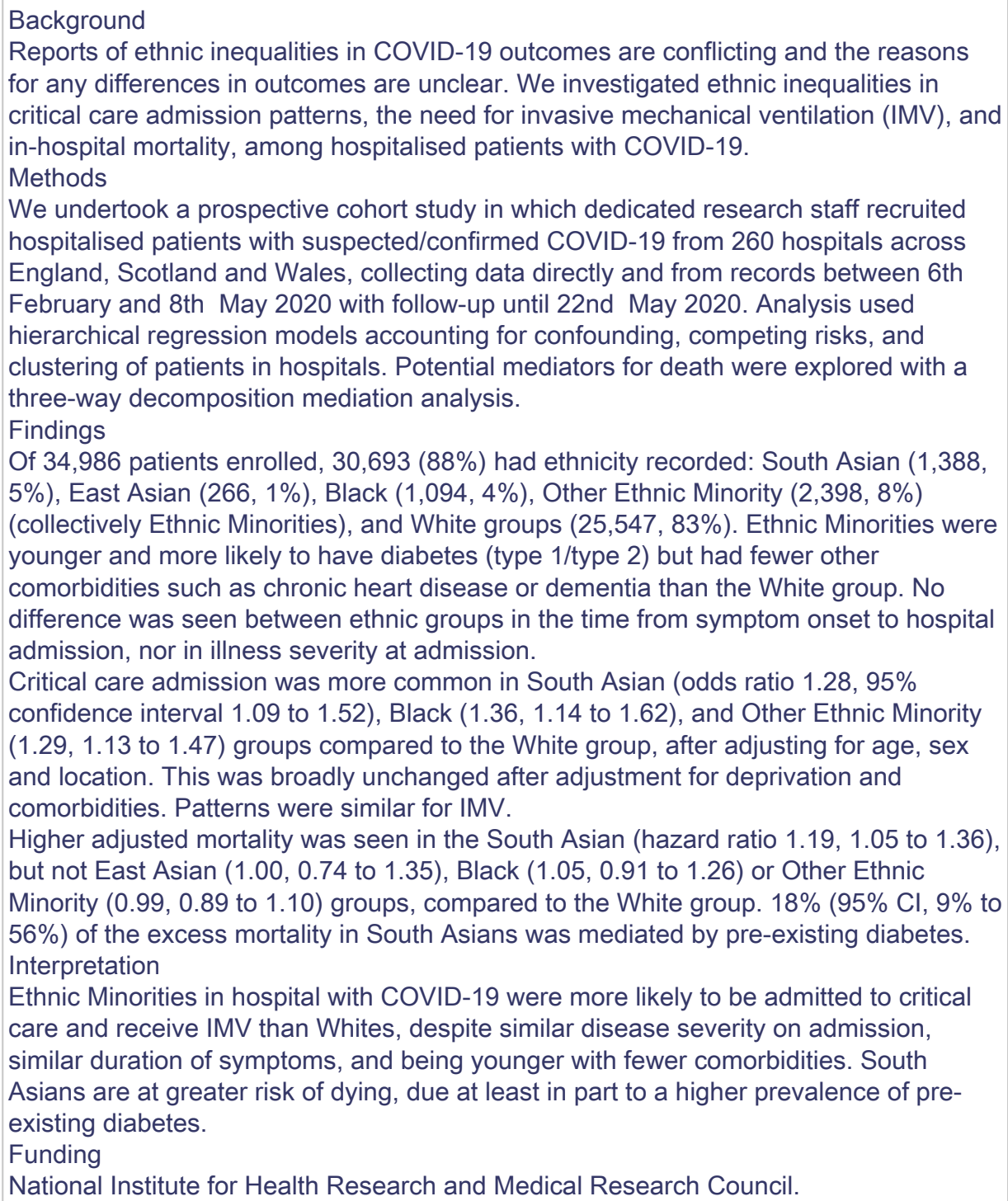 \\
\hline
\end{tabular}




\section{Ethnicity and outcomes from COVID-19: the ISARIC CCP-UK prospective observational cohort study of hospitalised patients}

Ewen M Harrison*1, Annemarie B Docherty ${ }^{1}$, Benjamin Barr², lain Buchan ${ }^{2}$, Gail Carson ${ }^{3}$, Tom M Drake ${ }^{1}$, Jake Dunning ${ }^{4,5}$, Cameron J Fairfield ${ }^{1}$, Carrol Gamble ${ }^{6}$, Christopher A Green ${ }^{7}$, Chris Griffiths ${ }^{8}$, Sophie Halpin ${ }^{6}$, Hayley E Hardwick ${ }^{9}$, Antonia $\mathrm{Ho}^{10}$, Karl A Holden ${ }^{11}$, Joe Hollinghurst ${ }^{12}$, Peter W Horby ${ }^{13}$, Clare Jackson ${ }^{7}, \mathrm{~S}$ Vittal Katikireddi ${ }^{14}$, Stephen Knight ${ }^{1}$, Ronan Lyons ${ }^{12}$, James MacMahon ${ }^{15}$, Kenneth A Mclean ${ }^{1}$, Laura Merson $^{3,16}$, Derek Murphy ${ }^{1}$, Jonathan S Nguyen-Van-Tam ${ }^{17}$, Lisa Norman ${ }^{1}$, Piero L Olliaro ${ }^{13}$, Manish Pareek ${ }^{18}$, Roberta Piroddi ${ }^{2}$, Riinu Pius ${ }^{1}$, Jonathan M Read ${ }^{19}$, Clark D Russel ${ }^{20}$, Naveed Sattar ${ }^{21}$, Catherine A Shaw ${ }^{1}$, Aziz Sheikh ${ }^{1}$, Ian P. Sinha ${ }^{11,22}$, Olivia Swann ${ }^{23}$, David Taylor-Robinson ${ }^{2}$, Daniel Thomas ${ }^{24}$, Lance Turtle ${ }^{9}$, Peter JM Openshaw $^{25}$, J Kenneth Baillie ${ }^{26,27}$, Malcolm G Semple ${ }^{9,22}$; on behalf of ISARIC4C†.

+ ISARIC4C investigators listed below

1. Centre for Medical Informatics, The Usher Institute, University of Edinburgh

2. Institute of Population Health Sciences, University of Liverpool

3. ISARIC Global Support Centre, Centre for Tropical Medicine and Global Health, Nuffield Department of Medicine, University of Oxford

4. National Infection Service, Public Health England

5. Faculty of Medicine, Imperial College London

6. Liverpool Clinical Trials Centre, University of Liverpool, Liverpool, UK

7. Institute of Microbiology \& Infection, University of Birmingham

8. Queen Mary University of London, Barts and The London School of Medicine and Dentistry

9. NIHR Health Protection Research Unit in Emerging and Zoonotic Infections, Institute of Infection, Veterinary \& Ecological Sciences, Faculty of Health and Life Sciences, University of Liverpool.

10. MRC University of Glasgow Centre for Virus Research, Glasgow.

11. Women's and Children's Health, Institute of Life Course and Medical Sciences, Faculty of Health and Life Sciences, University of Liverpool.

12. Swansea University

13. Centre for Tropical Medicine and International Health, Nuffield Department of Medicine, University of Oxford

14. MRC/CSO Social \& Public Health Sciences Unit, University of Glasgow

15. Public Health Scotland.

16. Infectious Diseases Data Observatory (IDDO), Centre for Tropical Medicine and Global Health, University of Oxford

17. Division of Epidemiology and Public Health, School of Medicine, University of Nottingham 
18. Department of Respiratory Sciences, University of Leicester

19. Centre for Health Informatics, Computing and Statistics, Lancaster Medical School, Lancaster University.

20. Queen's Medical Research Institute, University of Edinburgh.

21. Institute of Cardiovascular \& Medical Sciences, University of Glasgow.

22. Respiratory Medicine, Alder Hey Children's NHS Foundation Trust, Liverpool.

23. Department of Child Life and Health, University of Edinburgh.

24. Communicable Disease Surveillance Centre, Public Health Wales.

25. National Heart and Lung Institute, Faculty of Medicine, Imperial College London.

26. Roslin Institute, University of Edinburgh, Edinburgh, UK

27. Intensive Care Unit, Royal Infirmary Edinburgh, UK

* Corresponding author

Ewen M Harrison

Professor of Surgery and Data Science

Centre for Medical Informatics

Usher Institute

University of Edinburgh

Edinburgh EH16 4UX

07974420495

ewen.harrison@ed.ac.uk

@ewenharrison 


\section{Affiliations}

Ewen M Harrison, University of Edinburgh, Professor of Surgery and Data Science and Honorary Consultant Surgeon.

Annemarie Docherty, University of Edinburgh, Senior Clinical Lecturer and Honorary Consultant in Critical Care.

Benjamin Barr, University of Liverpool, Professor in Applied Public Health Research.

Iain Buchan, University of Liverpool, Executive Dean for Institute of Population Health Sciences and Professor of Public Health and Clinical Informatics.

Gail Carson, University of Oxford, Director at ISARIC Global Support Centre.

Tom M Drake, University of Edinburgh, Research Fellow.

Jake Dunning, Public Health England, Head of Emerging Infections and Zoonoses.

Cameron J Fairfield, University of Edinburgh, Research Fellow.

Carrol Gamble, University of Liverpool, Professor of Medical Statistics.

Christopher A. Green, University of Birmingham, Senior Clinical Lecturer \& Consultant Physician in Infectious Diseases.

Chris Griffiths, Queen Mary University of London, Barts and The London School of Medicine and Dentistry, Professor of Primary Care.

Sophie Halpin, University of Liverpool, Supervising Data Manager.

Hayley E Hardwick, University of Liverpool, Project Manager.

Antonia Ho, University of Glasgow, Clinical Senior Lecturer and Honorary Consultant in Infectious Diseases.

Karl A Holden, University of Liverpool, NIHR Academic Clinical Fellow in Paediatrics.

Joe Hollinghurst, Swansea University, Senior Data Scientist and Statistician

Peter W Horby, University of Oxford, Professor of Emerging Infectious Diseases.

Clare Jackson, University of Liverpool, Senior Data Manager.

S Vittal Katikireddi, University of Glasgow, Senior Clinical Research Fellow and Honorary Consultant in Public Health

Stephen Knight, University of Edinburgh, Research Fellow.

Ronan Lyons, Swansea University, Clinical Professor of Public Health.

James MacMahon, Public Health Scotland, Senior Information Analyst.

Kenneth A Mclean, University of Edinburgh, Research Fellow.

Laura Merson, University of Oxford, Associate Director Infectious Diseases Data Observatory and Head of Data ISARIC Global Support Centre.

Derek Murphy, University of Edinburgh, Senior Data Analyst. 
Jonathan S Nguyen-Van-Tam, University of Nottingham School of Medicine, Professor of Health Protection. Lisa Norman, University of Edinburgh, Research Assistant.

Piero L Olliaro, University of Oxford, Professor of Poverty Related Infectious Diseases.

Manish Pareek, University of Leicester, NIHR Associate Clinical Professor in Infectious Diseases.

Roberta Piroddi, University of Liverpool, Data Scientist.

Riinu Pius, University of Edinburgh, Senior Data Manager.

Jonathan M Read, Lancaster University, Senior Lecturer in Biostatistics.

Clark D Russell, University of Edinburgh, Clinical Lecturer.

Naveed Sattar, University of Glasgow, Professor of Metabolic Medicine.

Catherine A Shaw, University of Edinburgh, Senior Lecturer.

Aziz Sheikh, University of Edinburgh, Director, Usher Institute.

Ian P. Sinha, Alder Hey Children's NHS Foundation Trust Liverpool, Consultant Respiratory Paediatrician.

Olivia Swann, University of Edinburgh, Clinical Lecturer in Paediatric Infectious Disease.

David Taylor-Robinson, University of Liverpool, Professor of Public Health and Policy, Honorary Consultant in Child Public Health

Daniel Thomas, Public Health Wales, Head of Surveillance

Lance Turtle, University of Liverpool, Senior Clinical Lecturer in Infectious Diseases.

Peter JM Openshaw, Imperial College London, Professor of Experimental Medicine.

J Kenneth Baillie, University of Edinburgh, Academic Consultant in Critical Care Medicine.

Malcolm G Semple, University of Liverpool Professor of Outbreak Medicine and Child Health, Alder Hey Children's NHS Foundation Trust Liverpool Consultant Physician of Paediatric Respiratory Medicine. 


\section{Summary}

\section{Background}

Reports of ethnic inequalities in COVID-19 outcomes are conflicting and the reasons for any differences in outcomes are unclear. We investigated ethnic inequalities in critical care admission patterns, the need for invasive mechanical ventilation (IMV), and in-hospital mortality, among hospitalised patients with COVID-19.

\section{Methods}

We undertook a prospective cohort study in which dedicated research staff recruited hospitalised patients with suspected/confirmed COVID-19 from 260 hospitals across England, Scotland and Wales, collecting data directly and from records between $6^{\text {th }}$ February and $8^{\text {th }}$ May 2020 with follow-up until $22^{\text {nd }}$ May 2020. Analysis used hierarchical regression models accounting for confounding, competing risks, and clustering of patients in hospitals. Potential mediators for death were explored with a three-way decomposition mediation analysis.

Findings

Of 34,986 patients enrolled, 30,693 (88\%) had ethnicity recorded: South Asian (1,388, 5\%), East Asian (266, $1 \%)$, Black (1,094, 4\%), Other Ethnic Minority (2,398, 8\%) (collectively Ethnic Minorities), and White groups $(25,547,83 \%)$. Ethnic Minorities were younger and more likely to have diabetes (type 1/type 2 ) but had fewer other comorbidities such as chronic heart disease or dementia than the White group. No difference was seen between ethnic groups in the time from symptom onset to hospital admission, nor in illness severity at admission.

Critical care admission was more common in South Asian (odds ratio 1.28, 95\% confidence interval 1.09 to 1.52), Black (1.36, 1.14 to 1.62), and Other Ethnic Minority (1.29, 1.13 to 1.47) groups compared to the White group, after adjusting for age, sex and location. This was broadly unchanged after adjustment for deprivation and comorbidities. Patterns were similar for IMV.

Higher adjusted mortality was seen in the South Asian (hazard ratio 1.19, 1.05 to 1.36), but not East Asian $(1.00,0.74$ to 1.35$)$, Black $(1.05,0.91$ to 1.26$)$ or Other Ethnic Minority $(0.99,0.89$ to 1.10$)$ groups, compared to the White group. $18 \%(95 \% \mathrm{Cl}, 9 \%$ to $56 \%)$ of the excess mortality in South Asians was mediated by preexisting diabetes.

Interpretation

Ethnic Minorities in hospital with COVID-19 were more likely to be admitted to critical care and receive IMV than Whites, despite similar disease severity on admission, similar duration of symptoms, and being younger with fewer comorbidities. South Asians are at greater risk of dying, due at least in part to a higher prevalence of pre-existing diabetes.

Funding

National Institute for Health Research and Medical Research Council. 


\section{Research in Context}

Evidence before this study:

Evidence is emerging of an association between ethnicity and increased mortality in patients with COVID-19, as shown in a rapid evidence review by McQuillan et al. In a cohort study on the relative risk of COVID-19 infection by ethnic group, Niedzwiedz et al linked UK Biobank data to show that Black (relative risk 4.01 [95\% confidence interval 2.92 to 5.12]), South Asians (2.11 [1.43 to 3.10]) and White Irish (1.60 [1.08 to 2.38]) were more likely to have confirmed infection and were more likely to be hospitalised compared to White British. This relationship persisted after controlling for socioeconomic deprivation. In another study, de Noronha compared actual vs. expected hospital deaths and all ethnic groups other than White British and White Irish were found to have an age adjusted excess mortality. The UK Office of National Statistics used linked census and mortality records to show that age-adjusted COVID-19-related death was more four times more likely in Black individuals (odds ratio 4.2 [3.81 to 4.63]). When accounting for socioeconomic differences, Black (1.93 [1.70 to 2.18]) and Bangladeshi/Pakistani (1.81 [1.55 to 2.11]) individuals were still at significantly increased risk of death compared to the White group. The Intensive Care National Audit \& Research Centre (ICNARC) reported that $33 \%$ of patients critically ill with COVID-19 in England, Wales, and Northern Ireland are from non-White groups, compared to $12 \%$ with non-COVID-19 viral pneumonia in 2017 19.

\section{Added value of this study}

This is the largest prospective study of patients in hospital with COVID-19. We provide granular data on the stark differences in age and levels of comorbidity between White and Ethnic Minority people in hospital with COVID-19. We show high levels of use of critical care and invasive mechanical ventilation (IMV) in Ethnic Minorities compared with Whites, even after adjustment for age, sex, deprivation, and comorbidities, despite similar disease severity at presentation and similar times from symptom onset to hospital admission. We found a higher likelihood of death in hospital among South Asians with COVID-19, and for the first time show that a significant proportion of this risk was attributable to higher prevalence of diabetes.

Implications of all the available evidence

These findings have important implications for policy. Ethnicity should be accounted for in the prioritisation of prevention treatment and future vaccination policy. South Asians are over-represented in frontline key worker and public-interacting occupations, and guidance and policies should take this factor into account. Work is on-going to devise risk assessment tools to help mitigate the likelihood of coronavirus infection and manage the easing of lockdown restrictions. Careful consideration needs to be given in these tools to the weighting of ethnicity and mediators of risk such as diabetes. Further research integrating primary and secondary care data is key to improving the understanding of other drivers of poor outcomes among Ethnic Minorities. 


\section{Introduction}

The novel severe acute respiratory syndrome coronavirus SARS-CoV-2 has caused a pandemic, with 5.8 million reported as infected and over 360,000 reported to have died across the world. ${ }^{1}$ Studies from China, Italy and the UK have consistently reported that advanced age, comorbidity, and male sex are associated with increased mortality. ${ }^{2-4}$

COVID-19 deaths appear to disproportionately affect people from South Asian and Black ethnic backgrounds, but it is unclear if the incidence of infection is greater, the prognosis is worse once infected, or both. ${ }^{5-8}$ Patients from Asian, Black and other Minority Ethnic backgrounds are reported to have accounted for $34 \%$ of COVID-19 admissions to intensive care (ICU) in England, Wales and Northern Ireland, compared with only $12 \%$ for viral pneumonia (2017-2019), and a higher than expected proportion have required organ support and have died. ${ }^{9}$ Of NHS staff known to have died with COVID-19, 63 (63\%) were from an ethnic minority background. ${ }^{10}$ In the USA, the mortality rate for Black African Americans is quoted as 2.4 times higher than the rate for White Americans. ${ }^{11}$ It is unclear the extent to which differences in socioeconomic circumstances or pre-existing conditions may account for some or all such differences in risk. ${ }^{12}$

Ethnicity and socioeconomic position were associated with poor health outcomes during previous pandemics. ${ }^{13}$ The effect of ethnicity on outcome for pandemic influenza 2009 was explained in part by socioeconomic status. ${ }^{14}$ Ethnic minority groups may be at greater risk of infection, severe disease, and poor outcomes for multiple reasons. These include socioeconomic conditions that increase risks of transmission and vulnerability, such as overcrowded housing, ${ }^{15}$ employment in essential frontline occupations, ${ }^{16}$ poverty, healthcare seeking behaviours, ${ }^{17}$ and reliance on public transport. ${ }^{18}$ People living in more deprived areas in the UK have experienced COVID-19 mortality rates more than double those living in less deprived areas. ${ }^{19}$

Theoretical biological mechanisms for differences by ethnicity include susceptibility due to common comorbid illnesses such as diabetes and cardiovascular disease, ${ }^{20,21}$ or genetic factors associated with susceptibility or disease progression. Susceptibility to infectious disease, ${ }^{22}$ including influenza, ${ }^{23}$ and viral pneumonia, ${ }^{24}$ is strongly heritable, and early reports have suggested this is also true for COVID-19. ${ }^{25}$ Genetic variations in factors affecting viral entry ${ }^{26}$ or the host immune response ${ }^{27}$ may lead to differential susceptibility according to genetic heritage. Behavioural differences by ethnicity may also account for variability in healthcare outcomes.

In the wake of the A/H1N1pdm2009 influenza pandemic, the Clinical Characterisation Protocol UK (CCP-UK) for Severe Emerging Infection was developed by the International Severe Acute Respiratory and emerging Infections Consortium (ISARIC) and the World Health Organisation. As the pandemic potential of SARS-CoV-2 became apparent, the CCP was reactivated in the UK on $17^{\text {th }}$ January 2020 , in time to recruit the early patients admitted to hospitals with COVID-19. ${ }^{4}$

Our aim was to assess how prognosis in relation to critical care admission, use of invasive mechanical ventilation (IMV), and in-hospital mortality differs by ethnicity in the CCP-UK cohort of hospitalised patients with COVID-19. 


\section{Methods}

\section{Study design and setting}

ISARIC CCP-UK is an ongoing prospective cohort study involving 260 hospitals in England, Scotland, and Wales (table E1). The protocol, revision history, case report form, information leaflets, consent forms, and detail of the Independent Data and Material Access Committee (IDAMAC) are available at https://isaric4c.net. The study was approved by the South Central - Oxford C Research Ethics Committee in England (Ref: 13/SC/0149), and by the Scotland A Research Ethics Committee (Ref: 20/SS/0028). The STROBE guidelines were used when reporting.

\section{Participants}

Patients were included between $6^{\text {th }}$ February and $8^{\text {th }}$ May 2020 with follow-up until $22^{\text {nd }}$ May 2020 . Inclusion criteria were people of all ages who were admitted to hospital in England, Scotland, and Wales, with proven or a high likelihood of infection with SARS-CoV-2 leading to COVID-19 disease. Reverse transcriptase-PCR was the only mode of testing available during the period of study. The decision to test was at the discretion of the clinician attending the patient, and not defined by protocol. The enrolment criterion "high likelihood of infection" reflected that a preparedness protocol cannot assume a diagnostic test will be available for an emergent pathogen. In this activation, site training emphasised importance of only recruiting proven cases.

\section{Data collection}

Data were collected directly and extracted from routine healthcare records by research nurses, administrators and medical students, using case report forms on a REDCap (Research Electronic Data Capture, https://projectredcap.org) database. With consent, additional biological samples were collected for research. Data regarding illness progression and severity, including location within the hospital (ward vs. critical care) were collected on days 1 (admission/diagnosis), 3, 6, and 9, and on discharge/death, with further daily data collected on consented patients.

Self-reported ethnicity was transcribed from the healthcare record, where it had been recorded along with other demographics on admission. The care report form used an internationally applicable ethnicity definition with people categorised into East Asian, South Asian, West Asian, Black, White, Latin American, Aboriginal/First Nations and Other ethnic minority. ${ }^{28}$ For the purposes of this analysis, the collective Ethnic Minorities were collapsed into South Asian, East Asian, Black, Other Ethnic Minority (West Asian, Arab, Latin American, Aboriginal/First Nations, Other) and White, based on frequency (table E2).

Recorded comorbidities were asthma, diabetes (type 1 and type 2), chronic cardiac disease (excluding hypertension), chronic haematologic disease, chronic kidney disease, chronic neurological disorder, chronic pulmonary disease (excluding asthma), dementia, HIV/AIDS, malignancy, malnutrition, mild liver disease, moderate/severe liver disease, clinician-assigned obesity, rheumatologic disorder, and smoking.

As the home address was not available, the Index of Multiple Deprivation (IMD) and equivalents in Scotland and Wales, were used to create a hospital-weighted average deprivation score based on the admission population. Definitions varied between nations to accommodate data differences. For patients admitted in England, a weighted deprivation measure was aggregated by hospital catchment (admissions by Lower Layer Super Output Areas [LSOAs] determined from the Hospital Episode Statistics dataset and weighted by the relative contribution of each LSOA). For Wales, an average Welsh Index of Multiple Deprivation (WIMD) was constructed for each hospital by averaging the 2019 version of the WIMD from all admissions to hospital with a pneumonia or flu diagnosis in 2019 (ICD10: J09-J18). For Scotland, a weighted average of the Scottish Index of Multiple Deprivation (2018 mid-year data-zone estimates) was made at the hospital level and 
weighted for all non-elective admissions. To account for differences in the construction of these indices across the devolved nations, measures were centred, standardised, and incorporated with a random gradient into models.

\section{Outcomes}

The main outcomes were admission to a critical care facility (Intensive Care Unit [level 3] or High Dependency Unit [level 2]), use of IMV, and in-hospital mortality. To avoid potential bias in the assessment of outcomes where the sickest patients have the longest hospital stays, patients admitted to hospital between $8^{\text {th }}$ May and $22^{\text {nd }}$ May 2020 were excluded from outcome analyses.

As a measure of disease severity at admission, the National Early Warning Score 2 (NEWS2) was used. ${ }^{29}$ NEWS2 distributions were compared between groups and medians compared using the Mann-Whitney $U$ test. Time from symptom onset to admission was modelled using Cox Proportional Hazards regression.

\section{Statistical analyses}

Continuous data are presented as mean (standard deviation), or median (interquartile range) if substantially non-normally distributed. Binary data are presented as frequency (\%). Binomial confidence intervals for proportions were calculated using Wilson's method. ${ }^{30}$ For univariable comparisons, we used Welch's $t$, ANOVA, Mann-Whitney $U$, or Kruskal-Wallis tests according to data distribution. Categorical data were compared using chi-squared tests.

Our modelling strategy was informed by a putative causal graphical model (figure E1). Critical care admission and IMV use were modelled using hierarchical logistic regression models, adjusting for patient characteristics at level 1 and hospital of treatment at level 2. Baseline models included an adjustment for age, sex, and location. IMD was aggregated at hospital level, centred, and standardised, and allowed to vary as a random gradient by nation (level 3). Associations between ethnicity and comorbidity were modelled individually using logistic regression.

Survival was modelled using Cox Proportional Hazards regression, with alternative methods used for sensitivity analyses. Symptom onset was considered time zero. In the primary approach, discharge from hospital was considered an absorbing state (once discharged, patients were considered no longer at risk of death). Discharged patients were not censored and included in the risk set until the end of follow-up, thus discharge did not compete with death. Sensitivity analyses employed Fine \& Gray's competing risks method. ${ }^{31}$ Hierarchical Cox models included hospital as a random intercept and incorporated deprivation gradients varying by country. Parsimonious criterion-based model building used the following principles: relevant explanatory variables were identified via a causal graph a priori for exploration; age, sex, and hospital (random effects) were incorporated in baseline models; interactions were checked at first order level; final model selection was informed by the Akaike Information Criterion (AIC) and c-statistic for logistic regression models and c-statistic for survival models, with appropriate assumptions checked including the distribution of residuals and requirement for proportional hazards. The 30-day model-predicted mortality was calculated from the cumulative hazard for particular subgroups of interest and $95 \%$ confidence intervals determined by bootstrap resampling of models (5000 iterations).

A classical approach to mediation analysis in survival models was taken, extending into a three-way decomposition of total effect into direct, pure indirect, and mediated interactive effects. ${ }^{32} \mathrm{~A}$ priori hypotheses around the contribution of different comorbidities to mortality were explored, with comorbities associated with ethnicity entered into models sequentially. Associations between exposure and outcome, mediators and exposure, and mediators and outcome were characterised. Logistic regression models were 
fitted for mediators and Cox proportional survival models for outcomes, which were then combined.

Bootstrapping of estimates was performed to provide $95 \%$ confidence intervals $(95 \% \mathrm{Cls})$, together with a bootstrapped estimate of the mediated proportion of the total effect. All mediation models included age and sex as covariates.

\section{Missing data}

There were substantial levels of missing data due to the challenges of real-time data collection during a pandemic. Missing data are reported, and patterns of missing data explored (table E9). Multiple imputation of missing values was performed using chained equations for sensitivity analyses. Ten sets, each with 10 iterations, were imputed using available explanatory variables including the outcome. Missing ethnicity data were not imputed, but ethnicity was used in models for imputation. Graphical checks were performed, and imputed sets combined using Rubin's rules. ${ }^{33}$

Data were analysed using R (R Core Team v.3.6.3, Vienna, Austria) with packages including tidyverse, finalfit, survival, cmprsk, coxme and regmedint. 


\section{Results}

Between $6^{\text {th }}$ February and $8^{\text {th }}$ May 2020, we enrolled 34,986 patients admitted to 260 hospitals with COVID19 in England, Scotland, and Wales. This is estimated to represent $40.4 \%$ of all people admitted over that time period to hospital with COVID-19 in England, Scotland, and Wales.

\section{Presentation at hospital}

$30,693(88 \%)$ had ethnicity data recorded and were considered in the following groups: South Asians $(n=1,388,5 \%)$, East Asians (266, 1\%), Black (1,094, 4\%), Other Ethnic Minorities (2,398, 8\%), and Whites $(25,547,83 \%)$ (Figure 1).

Ethnic Minorities were younger (White mean 72 years (y) [standard deviation 16], South Asian 60 y [17], East Asian 60 y [17], Black 61 y [17], Other Ethnic Minority 62 y [18]) and more likely to have diabetes (South Asian $n=441$ [39.4\%], East Asian 71 [29.6\%], Black 384 [38.8\%], Other Ethnic Minority 636 [30.7\%]) compared to the White group (5838 [25.1\%]) (Table 1).

In unadjusted analysis, Whites were more likely than Ethnic Minorities to have other comorbidities such as chronic cardiac disease (White $n=8228$ [32.2\%], South Asian 266 [19.2\%], East Asian 47 [17.7\%], Black 162 [14.8\%], Other Ethnic Minority 467 [19.5\%]; non-asthmatic chronic pulmonary disease (White 4751 [18.6\%], South Asian 86 [6.2\%], East Asian 18 [6.8\%], Black 73 [6.7\%], Other Ethnic Minority 218 [9.1\%]); and dementia (White 4106 [16.1\%], South Asian 60 [4.3\%], East Asian 19 [7.1\%], Black 74 [6.8\%], Other Ethnic Minority $193[8.0 \%])$.

With age and sex adjustment, ethnic differences in comorbidity persisted with all Ethnic Minorities more likely to have diabetes (type 1 or type 2 ) and less likely to have non-asthmatic chronic pulmonary disease and obesity than the Whites (Figure 2). No difference in the likelihood of chronic cardiac disease was seen between South Asians and Whites.

No significant differences were seen in the distribution of severity scores (national early warning score 2 [NEWS2]) at admission between ethnic groups (figure 3A and figure $3 \mathrm{C}$ ). In patients presenting to hospital with COVID-19, no differences were seen in the time from symptom onset to admission between ethnic groups (figure $3 \mathrm{~B}$ ) when modelled using Cox proportion hazards methods for the relative hazard of admission (figure 3D).

\section{Ethnicity, critical care admission and invasive mechanical ventilation}

Overall, 4,353 patients (14\%) were admitted to a critical care facility (figure 4A). On unadjusted analysis, White individuals ( $n=3,258,13 \%)$ were less likely to be admitted to critical care than South Asian $(293,21 \%)$, East Asian (64, 24\%), Black (241, 22\%), or Other Ethnic Minority $(497,21 \%)$ people.

In models accounting for age, sex, and location (figure 5B), these associations persisted in South Asian (odds ratio $1.28,95 \%$ confidence interval 1.09 to 1.59 ), Black (1.36, 1.14 to 1.62), and Other Ethnic Minority (1.29, 1.13 to 1.47) (table E3) groups. No meaningful change in these estimates was seen with the sequential introduction of potential mediators including deprivation and comorbidities (diabetes, obesity, chronic cardiac disease, non-asthmatic chronic pulmonary disease, chronic kidney disease, and dementia) (figure 5C).

Similar findings were found in analyses of invasive mechanical ventilation (Figure E2, table E3). 


\section{Ethnicity and survival from COVID-19}

In analyses not accounting for age and sex differences between ethnic groups, in-hospital mortality occurred more frequently in the White group compared to the Ethnic Minorities (figure 4C, 6A). A sensitivity analysis excluding patients admitted in the most recent four weeks showed the same results (figure 4D).

However, in models accounting for age, sex, and location, evidence of higher mortality was seen in South Asian (hazard ratio 1.19, 1.05 to 1.36), but not East Asian (1.00, 0.74 to 1.35), Black (1.05, 0.91 to 1.21) or Other Ethnic Minority (0.99, 0.89 to 1.10) groups, compared to White group (figure 6B; table E5). No interaction was seen between ethnicity and age nor ethnicity and sex. Similar results were seen in alternative models of competing risks (table E10) and in models replaced in the ten multiple imputation sets (figure E3).

All associated comorbidities were explored as potential mediators of the apparent association between South Asian ethnicity and an increased hazard of death. Comorbidities associated with death in age- and sexadjusted analysis were explored (table E11 to E15). Of these, diabetes (hazard ratio 2.29, 1.99 to 2.62, P< $0.001)$ and chronic kidney disease $(1.66,1.38$ to $2.00, \mathrm{P}<0.001)$ had strong positive associations with South Asian ethnicity (figure 2).

A significant mediation effect (total natural indirect) of diabetes was found (hazard ratio 1.03, 1.02 to 1.04, $\mathrm{P}$ $<0.001$; table E16) representing $17.8 \%$ (8.9 to 65.7, P = 0.009; table E17) of the total effect of South Asian ethnicity on mortality (figure 7). Chronic kidney disease did not contribute significantly beyond the addition of diabetes to the model. Finally, to explore the relationship between age, diabetes and South Asian ethnicity, a Cox model was fitted including a three-way interaction (Figure 7B). The excess mortality was seen only in older South Asian patients. The association between diabetes and mortality was strongest in younger patients, compared with older. The diabetes effect was as strong in white patients, but the prevalence of diabetes higher in the South Asian group. 


\section{Discussion}

In this UK prospective cohort of 34,986 patients in hospital with COVID-19, patients from Ethnic Minority backgrounds were more likely to be admitted to critical care and to undergo IMV than White people, despite there being no difference in disease severity at presentation nor duration of symptoms and being substantially younger. South Asians in hospital with COVID-19 were $20 \%$ more likely to die than Whites, and $18 \%$ of this increased risk was mediated by higher prevalence of diabetes in the South Asian group. The higher risk of death was apparent in older South Asians, while the effect of diabetes was strongest in the young. This has significant implications given the younger age and higher prevalence of diabetes in South Asians admitted to hospital with COVID-19.

The ISARIC WHO CCP is the largest prospective observational cohort study of in-hospital patients with COVID-19 to date, now accounting for $40 \%$ of patients admitted to hospitals in the UK. It is the first study to look at in-hospital trajectories between different ethnic groups with COVID-19. We analysed the data with several separate approaches and our findings remained consistent. Our study has demonstrated the vital importance of forward planning and investment in preparedness studies: we were able to collect granular patient data in near-real time, and undertake analyses during the growth phase of the pandemic in the UK, without the delay associated with routine healthcare data linkages.

As this was a cohort of patients already admitted to hospital, we were unable to assess the risk of hospital admission or out-of-hospital mortality, leading to a potential risk of selection/collider bias when assessing mediators. Our analysis also does not take community factors into account such as population infection rates, exposure by employment, dose of exposure, and potential differential infection rates between different ethnic groups. Higher infection rates may be the result of bigger families, multi-generational households, urban residence, domestic overcrowding, and a greater proportion of individuals in direct public-interacting and healthcare occupations. Our analysis was also limited in the measurement of some key measures of health inequality: we did not have individual measures of socioeconomic status and had limited information on health behaviours such as smoking.

While we recruited $40 \%$ of patients admitted to hospital with COIVD-19, the results may reflect the differential risk in the whole hospital COVID-19 population, however we have no information on the $60 \%$ of patients who were not recruited. Our ethnicity definitions were designed to be broad for ease of data collection, but this reduced the ability to capture nuances in ethnicity. This limited our ability to explore these in greater depth, meaning that we may have missed differences within smaller groups. The Other Ethnic Minority group was likely to be heterogeneous. Obesity was defined by physician assignment and recorded as present or absent, rather than as $\mathrm{BMI}$, which may underrepresent obesity in Asian population where obesity is defined as BMI greater than 27.5. ${ }^{34}$ There were significant missing data given the nature of collecting prospective data at speed during a pandemic, but analyses of imputed datasets reflect those of the complete case analysis.

Characteristics of ethnic groups going into hospital were different: patients from non-White groups were younger and more likely to have diabetes compared with the White group, who were older and had more cardiac and respiratory disease. Variation in healthcare seeking behaviours and access to healthcare amongst more disadvantaged groups could also contribute to differences in the consequences of COVID$19,{ }^{18}$ however, we found no significant difference between ethnic groups in duration or severity of symptoms at hospital presentation in patients who were admitted.

Although the age-adjusted proportions of patients admitted to critical care was higher in the Ethnic Minority group, a large majority of patients admitted to critical care were White (White 75\%, South Asian 6.7\%, East Asian 1.5\%, Black 5.5\%, Other Ethnic Minority 11.4\%). This is a higher proportion compared with the latest 
ICNARC report, which found a two thirds of patients admitted to critical care were White. ${ }^{19}$ This may represent a selection bias in our cohort, or differences in definitions of critical care.

As reported in our earlier analysis, extreme elderly age and the presence of comorbidities were associated with a lower likelihood of critical care admission, suggesting advanced care planning decisions on the ward. ${ }^{4}$ While this may have disproportionately affected patients in the White group who were significantly older with more cardiac and respiratory disease, the increased likelihood of critical care admission and IMV in Ethnic Minorities persisted after adjustment. This may reflect an increased severity of disease in multiple Ethnic Minority populations, but falling short of significantly increased mortality in many.

Our finding of significantly increased mortality in the South Asian group is in agreement with reports which found that people from Asian and Black ethnic groups were at increased risk of in-hospital death from COVID-19, and that this was only partially attributable to pre-existing clinical risk factors or deprivation. $8,18,35$ We add an important and detailed picture of differences in characteristics of ethnic groups in hospital. The prevalence of diabetes is also striking at around $40 \%$ in South Asian and Black patients and the mediation of the mortality effect by diabetes is important. This appeared independent of chronic cardiac disease and chronic kidney disease and is likely to be due to the multitude of other negative health associations carried by the condition.

What of the increased mortality in South Asian patients left unexplained? Our models did not account well for wide socioeconomic determinants of outcome, as well as nuance in the comorbidity data. Socioeconomic inequalities contribute to differential exposure to infection, differential vulnerability following infection, and differential consequences of infection as well as control measures. ${ }^{36}$ In other studies, at Local Authority district level, the districts with a greater proportion of residents from non-White groups experienced higher COVID19 mortality rates, as did districts with a greater proportion of residents experiencing deprivation from low income. ${ }^{19}$ We did not find that deprivation at the level of the hospital was a significant predictor of time to hospital admission or severity of illness in hospital, however, aggregation of deprivation at hospital level masks individual socioeconomic effects. Future studies should examine the disaggregated effects where possible.

Why was excess mortality not apparent among our Black population, as others have reported? ${ }^{8}$ It seems unlikely this group are dying disproportionately in community compared with hospital settings, so any true effect should be visible in our cohort. Given that our study includes $40 \%$ of the UK hospitalised population, selection bias is clearly a possibility. On the other hand, it is possible that the estimates in our study are correct, given that some population-level reports rely on older census data as the denominator. Our ongoing work includes linking our dataset widely to better understand the place of the in-hospital stay as part of the full patient journey.

Finally, a subset of our cohort has consented to biological studies that can investigate potential biomechanistic differences in outcomes by ethnicity. Susceptibility to influenza ${ }^{23}$ is heritable, and it seems likely that this is also true for COVID-19. ${ }^{25}$ Ethnicity correlates with particular genetic polymorphisms which may link to important biological mechanisms mediating disease susceptibility and severity, for instance, relating to ACE2 receptor expression and SARS-CoV-2 cell entry. ${ }^{26}$

Our findings have important implications for policy makers and researchers. Given we illustrate increased disease severity across multiple hospitalised Ethnic Minority populations, ethnicity may need to be considered in the prioritisation of treatment and future vaccination policy. South Asians are overrepresented in frontline key worker and other direct public-interacting occupations, ${ }^{37}$ and policies should consider this factor in refining guidance and advice for at-risk individuals, accounting for age and comorbidity. On-going work to devise risk assessment tools to help mitigate the likelihood of SARS-CoV-2 
infection and manage the easing of individual lockdown restrictions needs to consider the effects of ethnicity on outcomes. Careful consideration also needs to be given in constructing these tools to the weighting of mediators of risk such as diabetes. Further research integrating primary and secondary care data is key to improving the understanding of other drivers of poor outcomes in Ethnic Minority patients. 


\section{References}

1. World Health Organisation (WHO). Coronavirus disease (COVID-19): Situation Report -131 [Internet]. 2020 [cited 2020 May 31]. Available from: https://www.who.int/docs/defaultsource/coronaviruse/situation-reports/20200530-covid-19-sitrep-131.pdf?sfvrsn=d31ba4b3_2

2. Chen N, Zhou M, Dong X, Qu J, Gong F, Han Y, et al. Epidemiological and clinical characteristics of 99 cases of 2019 novel coronavirus pneumonia in Wuhan, China: a descriptive study. Lancet. 2020 15;395(10223):507-13.

3. Onder G, Rezza G, Brusaferro S. Case-Fatality Rate and Characteristics of Patients Dying in Relation to COVID-19 in Italy. JAMA. 2020 Mar 23;

4. Docherty AB, Harrison EM, Green CA, Hardwick HE, Pius R, Norman L, et al. Features of 20133 UK patients in hospital with covid-19 using the ISARIC WHO Clinical Characterisation Protocol: prospective observational cohort study. BMJ [Internet]. 2020 May 22 [cited 2020 May 25];369. Available from: https://www.bmj.com/content/369/bmj.m1985

5. Bhala N, Curry G, Martineau AR, Agyemang C, Bhopal R. Sharpening the global focus on ethnicity and race in the time of COVID-19. The Lancet [Internet]. 2020 May 8 [cited 2020 May 25];0(0). Available from: https://www.thelancet.com/journals/lancet/article/PIIS0140-6736(20)31102-8/abstract

6. Niedzwiedz CL, O'Donnell CA, Jani BD, Demou E, Ho FK, Celis-Morales C, et al. Ethnic and socioeconomic differences in SARS-CoV-2 infection: prospective cohort study using UK Biobank. medRxiv. $2020 \mathrm{Apr}$ 30;2020.04.22.20075663.

7. Why are more black and minority ethnic people dying from Covid-19 in hospital? - Race Equality Foundation [Internet]. [cited 2020 May 25]. Available from:

https://raceequalityfoundation.org.uk/health-care/why-are-more-black-and-minority-ethnic-peopledying-from-covid-19-in-hospital/

8. Coronavirus (COVID-19) related deaths by ethnic group, England and Wales - Office for National Statistics [Internet]. [cited 2020 May 25]. Available from:

https://www.ons.gov.uk/peoplepopulationandcommunity/birthsdeathsandmarriages/deaths/articles/co ronavirusrelateddeathsbyethnicgroupenglandandwales/2march2020to10april2020

9. Intensive Care National Audit and Research Centre. ICNARC report on COVID-19 in critical care [Internet]. 2020 [cited 2020 May 25]. Available from: https://www.icnarc.org/OurAudit/Audits/Cmp/Reports

10. Cook T, Kursumovic E, April 2020 SL. Exclusive: deaths of NHS staff from covid-19 analysed [Internet]. Health Service Journal. [cited 2020 May 25]. Available from: https://www.hsj.co.uk/exclusive-deaths-ofnhs-staff-from-covid-19-analysed/7027471.article

11. COVID-19 deaths analyzed by race and ethnicity [Internet]. APM Research Lab. [cited 2020 May 25]. Available from: https://www.apmresearchlab.org/covid/deaths-by-race

12. Chowkwanyun M, Reed AL. Racial Health Disparities and Covid-19 - Caution and Context. New England Journal of Medicine. 2020 May 6;0(0):null.

13. Hutchins SS, Fiscella K, Levine RS, Ompad DC, McDonald M. Protection of Racial/Ethnic Minority Populations During an Influenza Pandemic. Am J Public Health. 2009 Oct;99(Suppl 2):S261-70. 
14. Nyland GA, McKenzie BC, Myles PR, Semple MG, Lim WS, Openshaw PJM, et al. Effect of ethnicity on care pathway and outcomes in patients hospitalized with influenza $A(H 1 N 1) p d m 09$ in the UK. Epidemiol Infect. 2015 Apr;143(6):1129-38.

15. Overcrowded households [Internet]. [cited 2020 May 25]. Available from: https://www.ethnicity-factsfigures.service.gov.uk/housing/housing-conditions/overcrowded-households/latest

16. Employment by occupation [Internet]. [cited 2020 May 25]. Available from: https://www.ethnicity-factsfigures.service.gov.uk/work-pay-and-benefits/employment/employment-by-occupation/latest

17. Haroon SMM, Barbosa GP, Saunders PJ. The determinants of health-seeking behaviour during the A/H1N1 influenza pandemic: an ecological study. J Public Health (Oxf). 2011 Dec;33(4):503-10.

18. Inequalities in COVID19 mortality related to ethnicity and socioeconomic deprivation | medRxiv [Internet]. [cited 2020 May 25]. Available from:

https://www.medrxiv.org/content/10.1101/2020.04.25.20079491v2

19. Deaths involving COVID-19 by local area and socioeconomic deprivation - Office for National Statistics [Internet]. [cited 2020 May 25]. Available from:

https://www.ons.gov.uk/peoplepopulationandcommunity/birthsdeathsandmarriages/deaths/bulletins/ deathsinvolvingcovid19bylocalareasanddeprivation/deathsoccurringbetween1marchand17april

20. Sattar Naveed, McInnes lain B., McMurray John J. V. Obesity a Risk Factor for Severe COVID-19 Infection: Multiple Potential Mechanisms. Circulation [Internet]. [cited 2020 May 25];0(0). Available from: https://www.ahajournals.org/doi/10.1161/CIRCULATIONAHA.120.047659

21. Bainey KR, Jugdutt BI. Increased burden of coronary artery disease in South-Asians living in North America. Need for an aggressive management algorithm. Atherosclerosis. 2009 May;204(1):1-10.

22. Sørensen TI, Nielsen GG, Andersen PK, Teasdale TW. Genetic and environmental influences on premature death in adult adoptees. N Engl J Med. 1988 Mar 24;318(12):727-32.

23. Baillie JK, Digard P. Influenza--time to target the host? N Engl J Med. 2013 Jul 11;369(2):191-3.

24. Patarčić I, Gelemanović A, Kirin M, Kolčić I, Theodoratou E, Baillie KJ, et al. The role of host genetic factors in respiratory tract infectious diseases: systematic review, meta-analyses and field synopsis. Sci Rep. 2015 Nov 3;5:16119.

25. Williams FM, Freydin M, Mangino M, Couvreur S, Visconti A, Bowyer RC, et al. Self-reported symptoms of covid-19 including symptoms most predictive of SARS-CoV-2 infection, are heritable. medRxiv. 2020 Apr 27;2020.04.22.20072124.

26. Single-cell RNA expression profiling of ACE2, the receptor of SARS-CoV-2 | bioRxiv [Internet]. [cited 2020 May 25]. Available from: https://www.biorxiv.org/content/10.1101/2020.01.26.919985v2

27. Cao K, Hollenbach J, Shi X, Shi W, Chopek M, Fernández-Viña MA. Analysis of the frequencies of HLA-A, $B$, and $C$ alleles and haplotypes in the five major ethnic groups of the United States reveals high levels of diversity in these loci and contrasting distribution patterns in these populations. Hum Immunol. 2001 Sep;62(9):1009-30.

28. Johnson MRD, Bhopal RS, Ingleby JD, Gruer L, Petrova-Benedict RS. A glossary for the first World Congress on Migration, Ethnicity, Race and Health. Public Health. 2019;172:85-8. 
29. Updated report of a working party. National Early Warning Score (NEWS) 2: Standardising the assessment of acute-illness severity in the NHS. Royal College of Physicians; 2017.

30. Newcombe RG. Interval estimation for the difference between independent proportions: comparison of eleven methods. Stat Med. 1998 Apr 30;17(8):873-90.

31. Fine JP, Gray RJ. A Proportional Hazards Model for the Subdistribution of a Competing Risk. Journal of the American Statistical Association. 1999;94(446):496-509.

32. VanderWeele TJ. A Three-way Decomposition of a Total Effect into Direct, Indirect, and Interactive Effects. Epidemiology. 2013 Mar;24(2):224-32.

33. Buuren S van, Groothuis-Oudshoorn K. mice: Multivariate Imputation by Chained Equations in R. Journal of Statistical Software. 2011 Dec 12;45(1):1-67.

34. Appropriate body-mass index for Asian populations and its implications for policy and intervention strategies. The Lancet. 2004 Jan 10;363(9403):157-63.

35. OpenSAFELY: factors associated with COVID-19-related hospital death in the linked electronic health records of 17 million adult NHS patients. | medRxiv [Internet]. [cited 2020 May 25]. Available from: https://www.medrxiv.org/content/10.1101/2020.05.06.20092999v1

36. Covid-19: We are not "all in it together" -less privileged in society are suffering the brunt of the damage [Internet]. The BMJ. 2020 [cited 2020 May 30]. Available from:

https://blogs.bmj.com/bmj/2020/05/22/covid-19-we-are-not-all-in-it-together-less-privileged-insociety-are-suffering-the-brunt-of-the-damage/

37. Critical workers who can access schools or educational settings [Internet]. GOV.UK. [cited 2020 May 31]. Available from: https://www.gov.uk/government/publications/coronavirus-covid-19-maintainingeducational-provision/guidance-for-schools-colleges-and-local-authorities-on-maintaining-educationalprovision 
Table 1. Characteristics of patients admitted to hospital with COVID-19 during between $6^{\text {th }}$ February 2020 and $8^{\text {th }}$ May 2020 by ethnic group. P-value is for a comparison across ethnic groups excluding missing data and is a chi-squared test for categorical variables and an F-test for continuous variables. Data $\mathrm{n}(\%)$ unless otherwise stated. IMD, index of multiple deprivation. 4,293 missing ethnicity (see table E9).

\begin{tabular}{|c|c|c|c|c|c|c|c|}
\hline Ethnicity & & White & South Asian & East Asian & Black & $\begin{array}{l}\text { Other Ethnic } \\
\text { Minority }\end{array}$ & $p$ \\
\hline Total N (\%) & & $25547(83.2)$ & $1388(4.5)$ & $266(0.9)$ & $1094(3.6)$ & $2398(7.8)$ & \\
\hline \multirow[t]{7}{*}{ Age on admission (years) } & Mean (SD) & $72.3(15.6)$ & $59.8(17.4)$ & $60.3(17.3)$ & 61.4 (17.3) & $62.4(17.8)$ & $<0.001$ \\
\hline & $18-39$ & $1025(4.0)$ & $180(13.0)$ & $32(12.0)$ & $126(11.5)$ & 275 (11.5) & \\
\hline & $40-49$ & $1308(5.1)$ & $243(17.5)$ & $43(16.2)$ & $140(12.8)$ & 336 (14.0) & \\
\hline & $50-59$ & 2962 (11.6) & 248 (17.9) & $57(21.4)$ & $273(25.0)$ & 432 (18.0) & \\
\hline & $60-69$ & 3928 (15.4) & $286(20.6)$ & $43(16.2)$ & $197(18.0)$ & 431 (18.0) & \\
\hline & $70-79$ & 6319 (24.7) & 222 (16.0) & $46(17.3)$ & 143 (13.1) & 430 (17.9) & \\
\hline & $80+$ & 10005 (39.2) & 209 (15.1) & 45 (16.9) & 215 (19.7) & 494 (20.6) & \\
\hline \multirow[t]{3}{*}{ Sex at Birth } & Male & $14684(57.5)$ & $887(63.9)$ & $174(65.4)$ & $602(55.0)$ & $1426(59.5)$ & $<0.001$ \\
\hline & Female & $10778(42.2)$ & $500(36.0)$ & $91(34.2)$ & 490 (44.8) & 964 (40.2) & \\
\hline & (Missing) & $85(0.3)$ & $1(0.1)$ & $1(0.4)$ & $2(0.2)$ & $8(0.3)$ & \\
\hline \multirow[t]{2}{*}{ Diabetes } & No & $17447(74.9)$ & $679(60.6)$ & $169(70.4)$ & $606(61.2)$ & 1435 (69.3) & $<0.001$ \\
\hline & Yes & $5838(25.1)$ & 441 (39.4) & $71(29.6)$ & $384(38.8)$ & $636(30.7)$ & \\
\hline \multirow[t]{3}{*}{ Obesity } & No & $18952(74.2)$ & $910(65.6)$ & 207 (77.8) & 804 (73.5) & $1718(71.6)$ & 0.201 \\
\hline & Yes & $2382(9.3)$ & $114(8.2)$ & $19(7.1)$ & $123(11.2)$ & $210(8.8)$ & \\
\hline & (Missing) & 4213 (16.5) & $364(26.2)$ & $40(15.0)$ & $167(15.3)$ & 470 (19.6) & \\
\hline \multirow[t]{3}{*}{ Chronic cardiac disease } & No & $15403(60.3)$ & 867 (62.5) & 195 (73.3) & 841 (76.9) & 1629 (67.9) & $<0.001$ \\
\hline & Yes & $8228(32.2)$ & 266 (19.2) & 47 (17.7) & $162(14.8)$ & 467 (19.5) & \\
\hline & (Missing) & $1916(7.5)$ & 255 (18.4) & $24(9.0)$ & $91(8.3)$ & 302 (12.6) & \\
\hline \multirow[t]{3}{*}{ Chronic pulmonary disease } & No & $18821(73.7)$ & $1043(75.1)$ & $223(83.8)$ & 929 (84.9) & $1857(77.4)$ & $<0.001$ \\
\hline & Yes & 4751 (18.6) & $86(6.2)$ & $18(6.8)$ & $73(6.7)$ & $218(9.1)$ & \\
\hline & (Missing) & $1975(7.7)$ & $259(18.7)$ & $25(9.4)$ & $92(8.4)$ & $323(13.5)$ & \\
\hline \multirow[t]{3}{*}{ Asthma } & No & $20079(78.6)$ & 945 (68.1) & 207 (77.8) & 870 (79.5) & $1803(75.2)$ & 0.108 \\
\hline & Yes & 3358 (13.1) & $188(13.5)$ & $34(12.8)$ & 129 (11.8) & 281 (11.7) & \\
\hline & (Missing) & $2110(8.3)$ & 255 (18.4) & $25(9.4)$ & 95 (8.7) & $314(13.1)$ & \\
\hline \multirow[t]{3}{*}{ Chronic kidney disease } & No & $19201(75.2)$ & 931 (67.1) & $218(82.0)$ & 831 (76.0) & 1796 (74.9) & $<0.001$ \\
\hline & Yes & 4208 (16.5) & 193 (13.9) & $26(9.8)$ & 170 (15.5) & 286 (11.9) & \\
\hline & (Missing) & $2138(8.4)$ & $264(19.0)$ & $22(8.3)$ & $93(8.5)$ & $316(13.2)$ & \\
\hline \multirow[t]{3}{*}{ Moderate/severe liver disease } & No & $22739(89.0)$ & $1102(79.4)$ & $237(89.1)$ & $976(89.2)$ & 2012 (83.9) & 0.221 \\
\hline & Yes & 460 (1.8) & $13(0.9)$ & $2(0.8)$ & $17(1.6)$ & $37(1.5)$ & \\
\hline & (Missing) & $2348(9.2)$ & $273(19.7)$ & $27(10.2)$ & $101(9.2)$ & $349(14.6)$ & \\
\hline \multirow[t]{3}{*}{ Mild liver disease } & No & $22798(89.2)$ & $1096(79.0)$ & $233(87.6)$ & 979 (89.5) & $2006(83.7)$ & 0.719 \\
\hline & Yes & 344 (1.3) & $18(1.3)$ & $6(2.3)$ & $13(1.2)$ & $32(1.3)$ & \\
\hline & (Missing) & $2405(9.4)$ & $274(19.7)$ & $27(10.2)$ & $102(9.3)$ & $360(15.0)$ & \\
\hline \multirow[t]{3}{*}{ Chronic neurological disorder } & No & $20243(79.2)$ & $1045(75.3)$ & $221(83.1)$ & $928(84.8)$ & $1870(78.0)$ & $<0.001$ \\
\hline & Yes & 3032 (11.9) & $78(5.6)$ & 21 (7.9) & $68(6.2)$ & $183(7.6)$ & \\
\hline & (Missing) & $2272(8.9)$ & 265 (19.1) & $24(9.0)$ & $98(9.0)$ & $345(14.4)$ & \\
\hline \multirow[t]{3}{*}{ Malignancy } & No & 20665 (80.9) & $1072(77.2)$ & $229(86.1)$ & 915 (83.6) & 1910 (79.6) & $<0.001$ \\
\hline & Yes & 2530 (9.9) & $48(3.5)$ & $9(3.4)$ & 85 (7.8) & $144(6.0)$ & \\
\hline & (Missing) & $2352(9.2)$ & $268(19.3)$ & $28(10.5)$ & $94(8.6)$ & $344(14.3)$ & \\
\hline Chronic haematologic disease & No & 22195 (86.9) & $1085(78.2)$ & $232(87.2)$ & $922(84.3)$ & $1971(82.2)$ & $<0.001$ \\
\hline
\end{tabular}




\section{AIDS/HIV}

Rheumatologic disorder

Dementia

Malnutrition

Smoking

Prior immunosuppression

Prior infection treatment

Deprivation (IMD)
Yes

(Missing)

No

Yes

(Missing)

No

Yes

(Missing)

No

Yes

(Missing)

No

Yes

(Missing)

Yes

Never

Smoked

Former

Smoker

(Missing)

No

Yes

(Missing)

No

Yes

(Missing)

Mean (SD)
975 (3.8)

2377 (9.3)

22931 (89.8)

$74(0.3)$

$2542(10.0)$

20412 (79.9)

2717 (10.6)

2418 (9.5)

19252 (75.4)

4106 (16.1)

2189 (8.6)

21456 (84.0)

607 (2.4)

3484 (13.6)

$1266(5.0)$

9271 (36.3)

$6310(24.7)$

8700 (34.1)

20734 (81.2)

2329 (9.1)

2484 (9.7)

18342 (71.8)

4659 (18.2)

2546 (10.0)

$0.1(0.8)$

$\begin{array}{rrrrr}33(2.4) & 8(3.0) & 76(6.9) & 80(3.3) & \\ 270(19.5) & 26(9.8) & 96(8.8) & 347(14.5) & \\ 1092(78.7) & 239(89.8) & 947(86.6) & 2020(84.2) & <0.001 \\ 4(0.3) & 1(0.4) & 34(3.1) & 9(0.4) & \\ 292(21.0) & 26(9.8) & 113(10.3) & 369(15.4) & \\ 1042(75.1) & 230(86.5) & 936(85.6) & 1899(79.2) & <0.001 \\ 67(4.8) & 8(3.0) & 62(5.7) & 141(5.9) & \\ 279(20.1) & 28(10.5) & 96(8.8) & 358(14.9) & \\ 1055(76.0) & 220(82.7) & 933(85.3) & 1872(78.1) & <0.001 \\ 60(4.3) & 19(7.1) & 74(6.8) & 193(8.0) & \\ 273(19.7) & 27(10.2) & 87(8.0) & 333(13.9) & \\ 1050(75.6) & 225(84.6) & 948(86.7) & 1922(80.2) & 0.031 \\ 20(1.4) & 5(1.9) & 13(1.2) & 46(1.9) & \\ 318(22.9) & 36(13.5) & 133(12.2) & 430(17.9) & \\ 34(2.4) & 9(3.4) & 27(2.5) & 95(4.0) & <0.001 \\ 744(53.6) & 142(53.4) & 609(55.7) & 1133(47.2) & \\ 126(9.1) & 34(12.8) & 114(10.4) & 332(13.8) & \\ 484(34.9) & 81(30.5) & 344(31.4) & 838(34.9) & \\ 1027(74.0) & 216(81.2) & 907(82.9) & 1906(79.5) & 0.003 \\ 88(6.3) & 15(5.6) & 86(7.9) & 173(7.2) & \\ 273(19.7) & 35(13.2) & 101(9.2) & 319(13.3) & \\ 892(64.3) & 187(70.3) & 817(74.7) & 1672(69.7) & 0.193 \\ 216(15.6) & 44(16.5) & 176(16.1) & 389(16.2) & \\ 280(20.2) & 35(13.2) & 101(9.2) & 337(14.1) & \\ 0.1(0.8) & 0.2(0.8) & 0.1(0.7) & 0.3(0.7) & <0.001\end{array}$


Figure 1. Patient inclusion stratified by ethnicity. Critical care use, invasive mechanical ventilation, and mortality in all included patients.

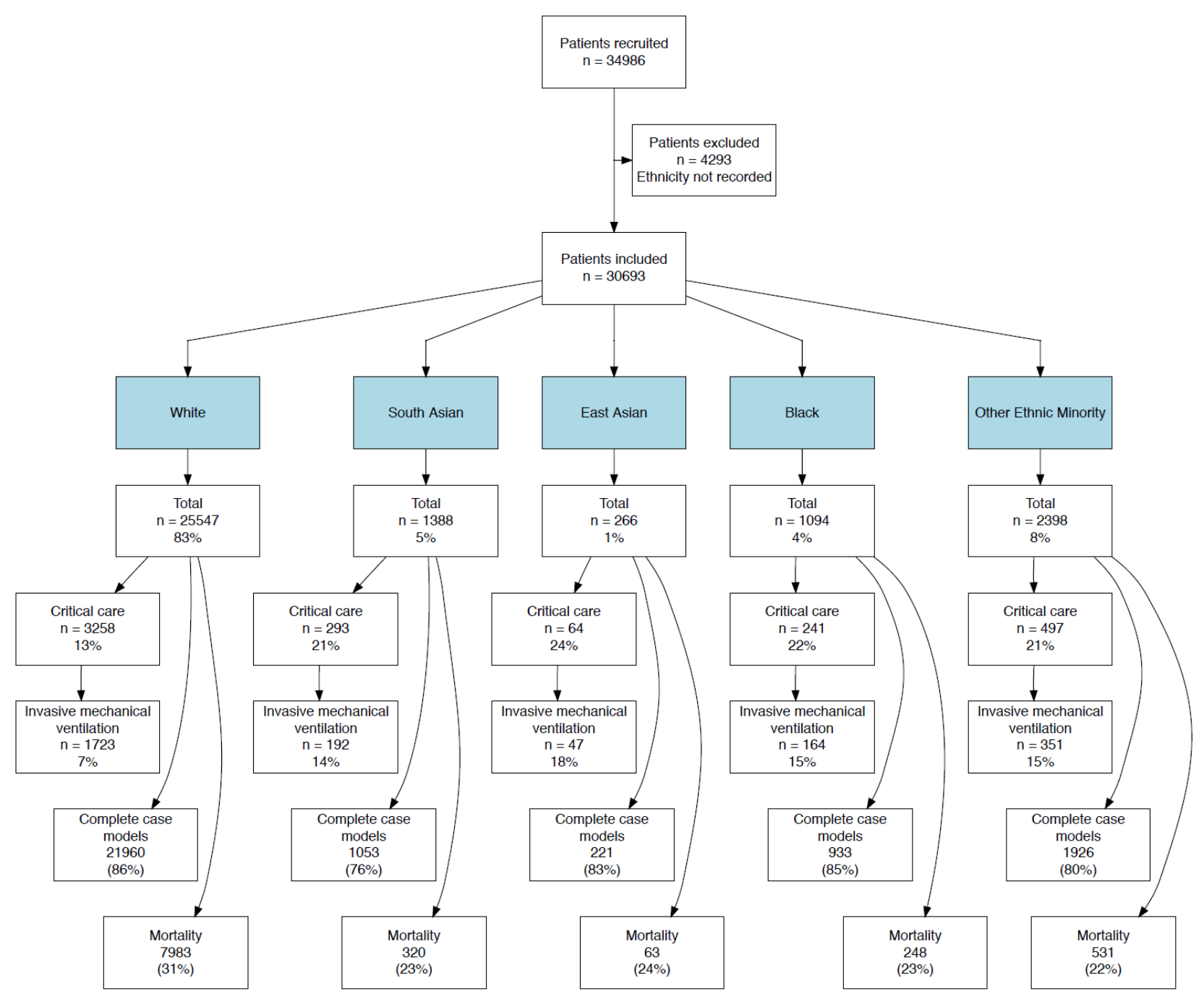


Figure 2. Age and sex adjusted association between ethnicity and comorbidity for patients in hospital with COVID-19. Hierarchical logistic regression models of complete data. Data are odds ratios (95\% confidence interval, P-value).

A Diabetes

Ethnicity

$$
\begin{array}{r}
\text { White } \\
\text { South Asian } \\
\text { East Asian } \\
\text { Black } \\
\text { Other Ethnic Minority }
\end{array}
$$

B Obesity

Ethnicity

White

South Asian

East Asian

Black

Other Ethnic Minority

C Chronic cardiac disease

Ethnicity

White

South Asian

East Asian

Black

Other Ethnic Minority

$D$ Chronic pulmonary disease

Ethnicity

White

South Asian

East Asian

Black

Other Ethnic Minority

E Chronic kidney disease Ethnicity

White South Asian

East Asian

Black

Other Ethnic Minority

F Dementia Ethnicity

White

South Asian

East Asian

Black

Other Ethnic Minority
$2.29(1.99-2.62, \mathrm{p}<0.001)$

$1.51(1.11-2.04, p=0.008)$

$2.30(1.99-2.65, p<0.001)$

$1.46(1.30-1.62, p<0.001)$

$0.76(0.64-0.90, p=0.002)$

$0.57(0.38-0.86, p=0.007)$

$1.04(0.87-1.25, p=0.664)$

$0.83(0.73-0.95, p=0.008)$

$1.03(0.87-1.22, p=0.717)$

$0.81(0.55-1.17, p=0.260)$

$0.60(0.49-0.73, p<0.001)$

$0.74(0.65-0.84, p<0.001)$

$0.49(0.39-0.63, p<0.001)$ $0.44(0.26-0.77, p=0.004)$ 0.45 (0.34-0.59, $p<0.001)$ $0.62(0.53-0.73, p<0.001)$

$1.66(1.38-2.00, p<0.001)$ $0.87(0.54-1.40, p=0.557)$

$1.59(1.30-1.93, p<0.001)$

$0.88(0.76-1.04, p=0.127)$

$0.62(0.46-0.83, p=0.001)$

$0.99(0.57-1.71, p=0.976)$

$0.63(0.47-0.85, p=0.002)$

$0.80(0.67-0.97, p=0.020)$
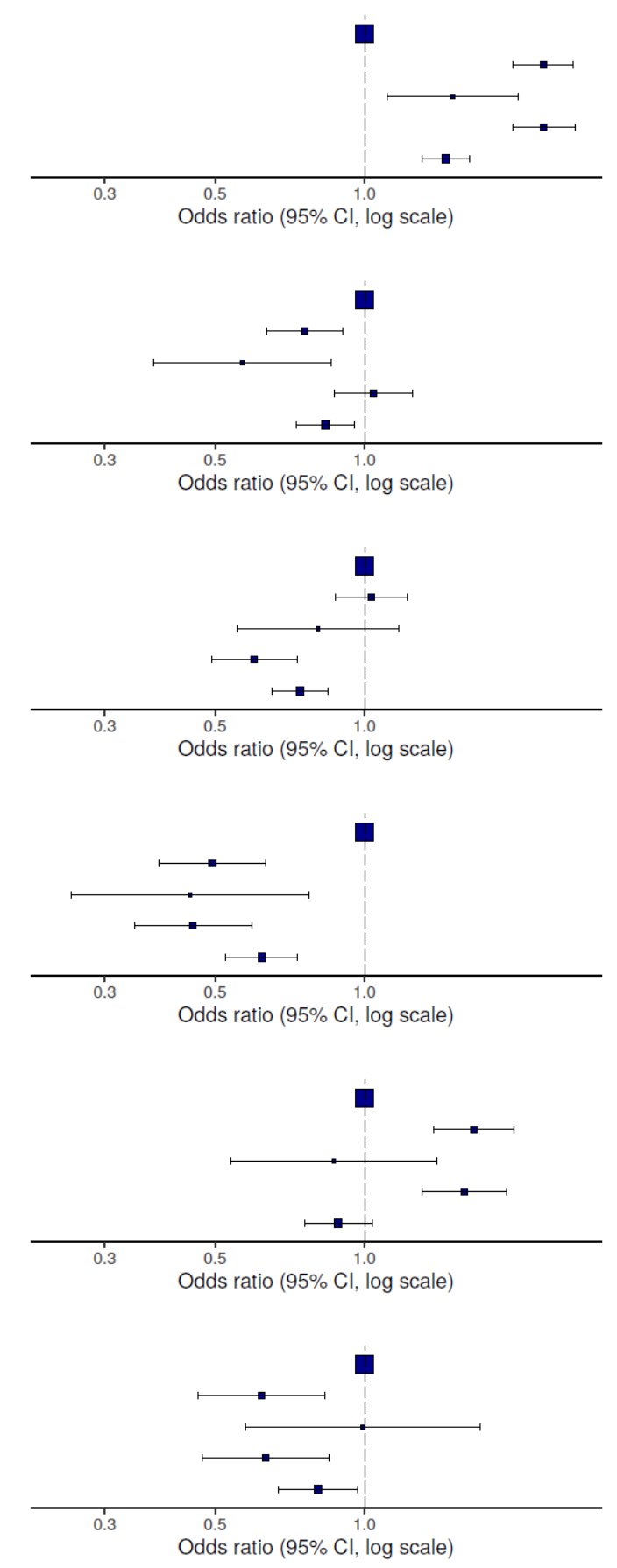
Figure 3. Severity score at admission and time from symptom onset to admission by ethnicity. National early warning score 2 (NEWS2) distribution (A) and proportion with NEWS2 >2 (C) by ethnicity. In patients presenting to hospital with COVID-19, distribution of time from symptom onset to admission (B) and Cox proportion hazards model of time to admission showing relative hazard for admission by ethnicity adjusted for age and sex (D).

A Severity score (NEWS2) on admission

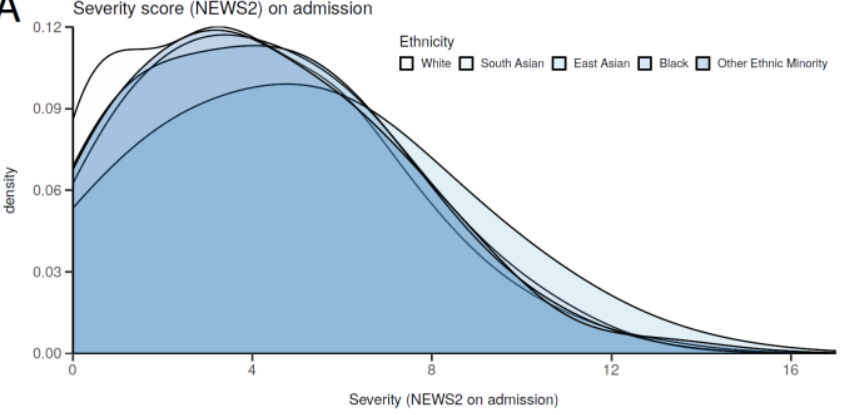

C Patients with NEWS2 score $>2$ on admission to hospital with COVID-19

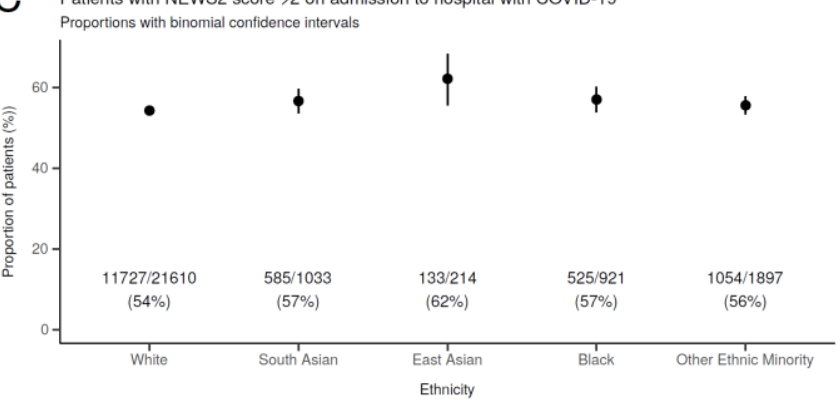

B Time from symptom onset to admission

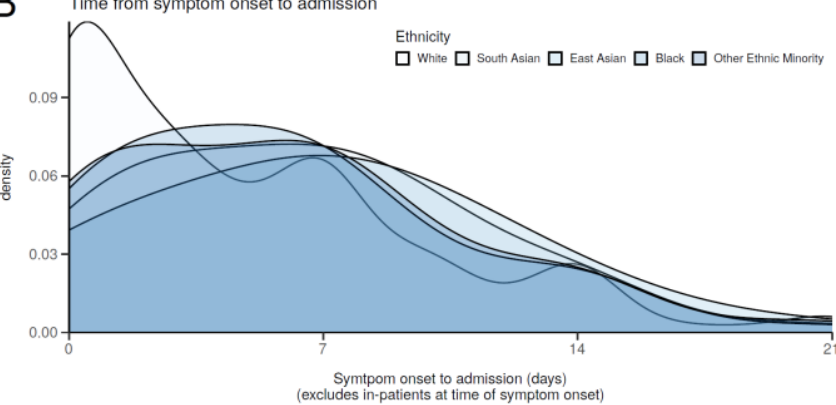

D Time to admission: hazard ratio ( $95 \%$ confidence interval)

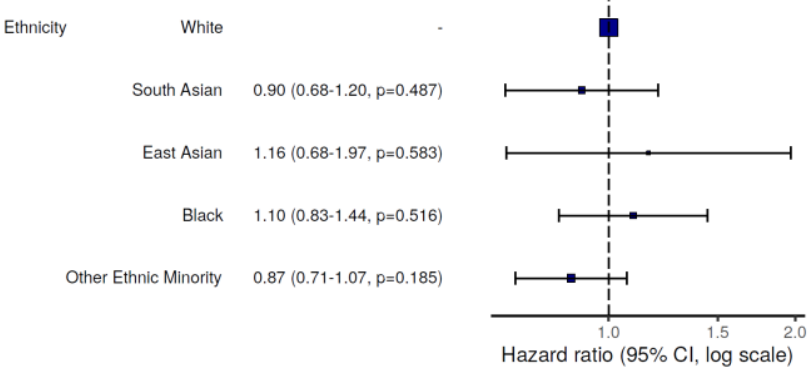


Figure 4. Unadjusted critical care admission (A), use of invasive mechanical ventilation (B), case fatality in patients with at least 2 weeks follow-up (C) and with at least 4 weeks follow-up (D) by ethnicity. Proportions from crude counts with no adjustment for age, sex, or clustering. Binomial confidence intervals. Numbers are patient counts per group / total cohort (\%). IMV, invasive mechanical ventilation.
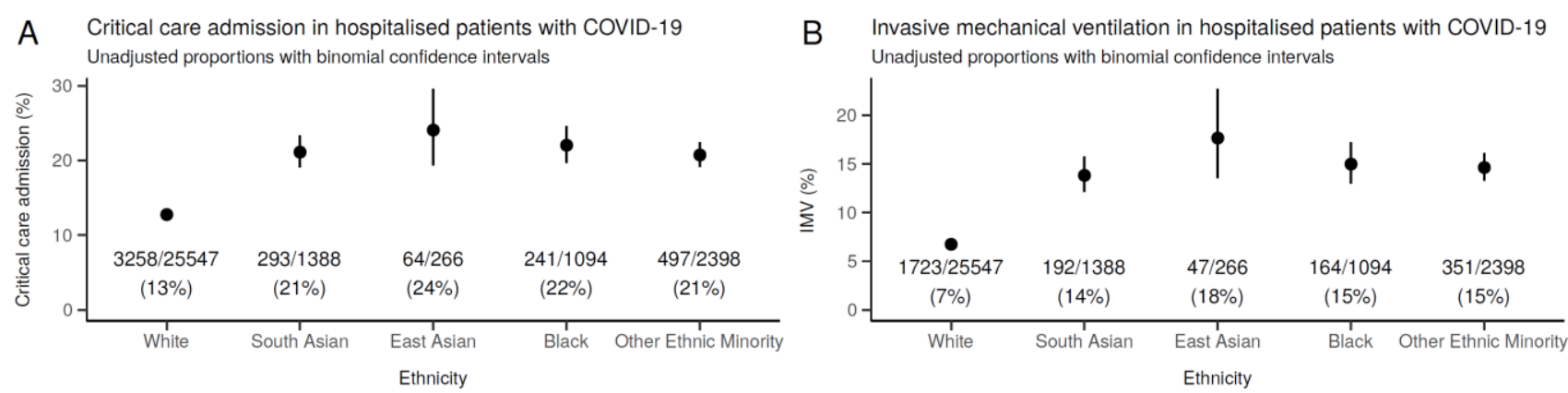

C Case fatality in patients with $>2$ weeks follow-up

D Case fatality in patients with $>30$ days follow-up
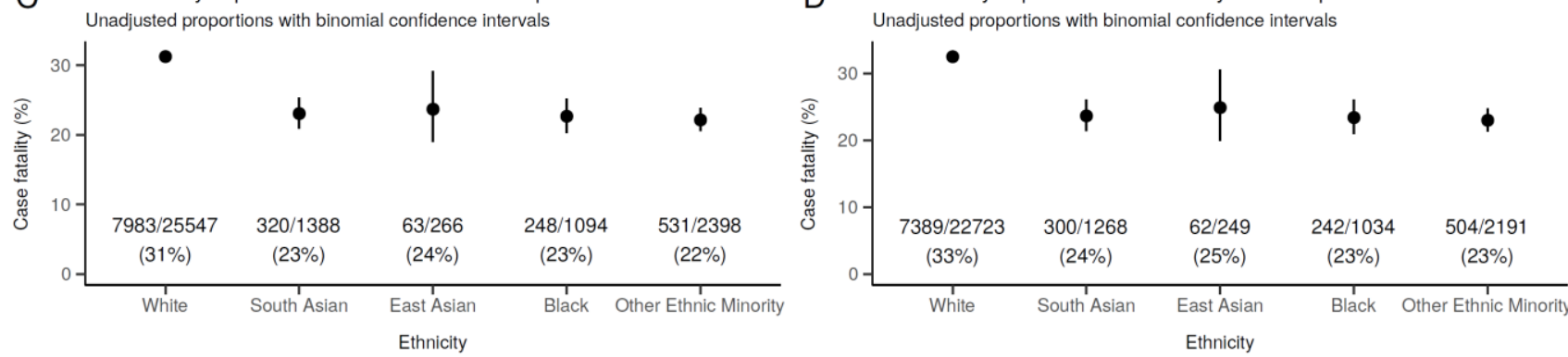
Figure 5. Critical care admission by ethnic group. (A) Univariable logistic regression model of ethnicity alone. (B) Hierarchical logistic regression model adjusting for age, sex and accounting for clustering in hospitals. (C) Hierarchical logistic regression models with adjustment for factors potentially mediating critical care admission were explored sequentially. Full model presented here accepting potential bias in comorbidity estimates. Complete case data. See table E3 for full models. Size of point estimate box proportional to population size. IMD, index of multiple deprivation (centred and standardised).

A Critical care admission: ethnicity alone Ethnicity

South Asian
East Asian
Black
Other Ethnic Minority

B Critical care: hierarchical baseline Ethnicity

$\begin{array}{cr} & \text { South Asian } \\ & \text { East Asian } \\ \text { Black } \\ \text { Other Ethnic Minority } \\ \text { Age on admission (years) } & 50-59 \\ & 18-39 \\ 40-49 \\ 60-69 \\ 70-79 \\ 80+ \\ \text { Sex at Birth }\end{array}$

C Critical care: hierarchical with potential mediators

$\begin{array}{lrr}\text { Ethnicity } & \begin{array}{c}\text { White } \\ \text { South Asian }\end{array} & 1.32(1.12-1.56, \mathrm{p}=0.001) \\ & \text { East Asian } & 1.30(0.93-1.81, \mathrm{p}=0.127) \\ & \text { Black } & 1.34(1.12-1.61, \mathrm{p}=0.001) \\ & \text { Other Ethnic Minority } & 1.26(1.10-1.44, \mathrm{p}=0.001) \\ \text { Age on admission (years) } & 50-59 & 0.55(0.47-0.64, \mathrm{p}<0.001) \\ & 18-39 & 0.86(0.75-0.98, \mathrm{p}=0.026) \\ & 40-49 & 0.95(0.86-1.06, \mathrm{p}=0.378) \\ & 60-69 & 0.56(0.50-0.62, \mathrm{p}<0.001) \\ & 70-79 & 0.16(0.14-0.19, \mathrm{p}<0.001) \\ & 80+ & 0.56(0.52-0.61, \mathrm{p}<0.001) \\ \text { Sex at Birth } & \text { Female } & 1.03(0.76-1.39, \mathrm{p}=0.873) \\ \text { Deprivation (IMD) } & - & 1.00(0.92-1.09, \mathrm{p}=0.969) \\ \text { Diabetes } & \text { Yes } & \\ \text { Obesity } & \text { No } & 1.79(1.61-2.00, \mathrm{p}<0.001) \\ & \text { Yes } & 1.07(0.92-1.24, \mathrm{p}=0.373) \\ & \text { (Missing) } & 0.64(0.57-0.71, \mathrm{p}<0.001) \\ \text { Chronic cardiac disease } & \text { Yes } & 0.71(0.63-0.80, \mathrm{p}<0.001) \\ \text { Chronic pulmonary disease } & \text { Yes } & 0.66(0.57-0.75, \mathrm{p}<0.001) \\ \text { Chronic kidney disease } & \text { Yes } & 0.26(0.21-0.33, p<0.001) \\ \text { Dementia } & \text { Yes } & \end{array}$

$2.07(1.78-2.39, p<0.001)$

$2.16(1.57-2.91, p<0.001)$

1.96 (1.67-2.29, $p<0.001)$

$1.82(1.62-2.04, p<0.001)$

$1.28(1.09-1.52, p=0.003)$

$1.29(0.92-1.79, p=0.136)$

$1.36(1.14-1.62, p=0.001)$

$1.29(1.13-1.47, p<0.001)$

$0.58(0.50-0.68, p<0.001)$

$0.89(0.78-1.01, p=0.080)$

$0.84(0.75-0.93, p=0.001)$

$0.39(0.35-0.44, p<0.001$

$0.09(0.08-0.10, p<0.001)$

$0.59(0.55-0.64, p<0.001)$
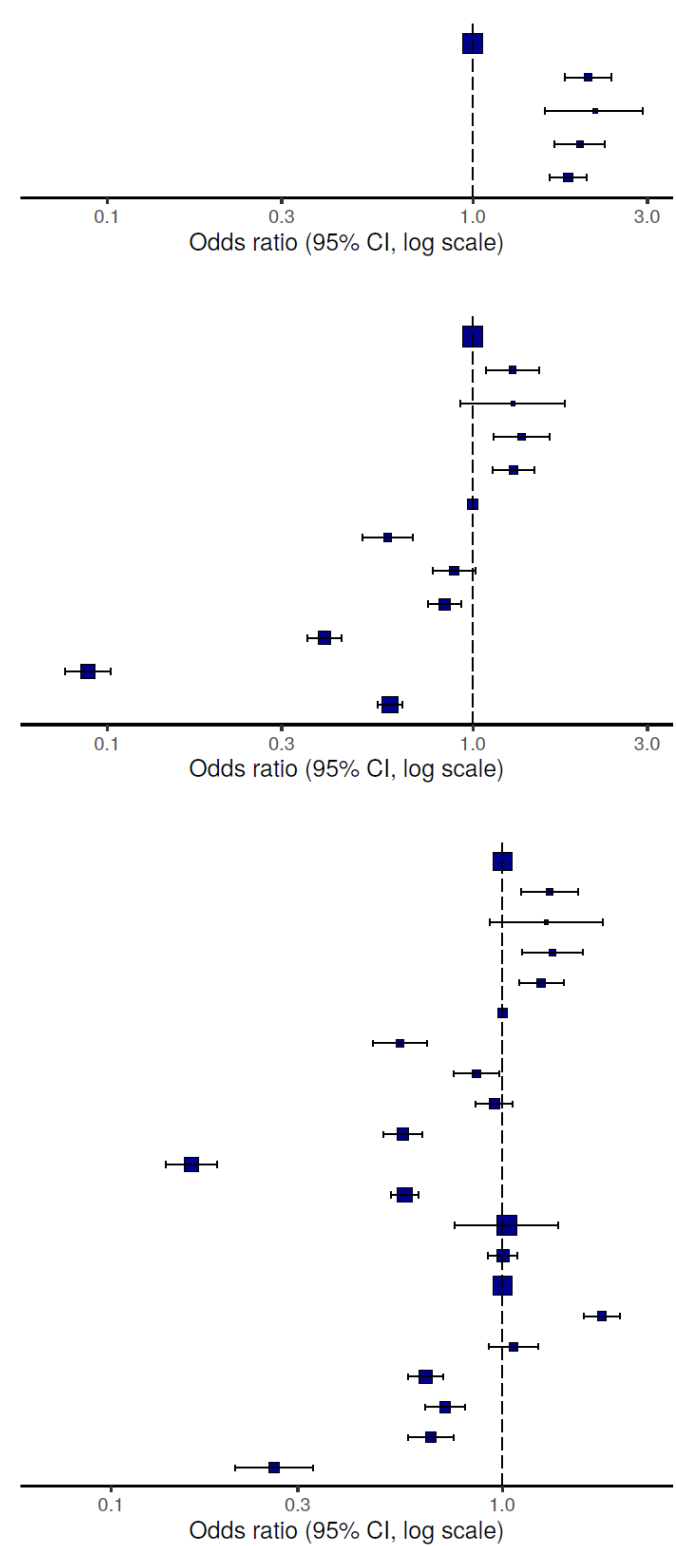
Figure 6. In-hospital survival by ethnic group. Estimates are hazard ratio ( $95 \%$ confidence interval, P-value). (A) Univariable Cox proportional hazards regression model of ethnicity alone. (B) Hierarchical Cox proportional hazards regression model adjusting for age, sex and deprivation, accounting for clustering within hospital. (C) Hierarchical Cox proportional hazards regression models with adjustment for factors potentially mediating survival by ethnic group were explored sequentially. accounting for clustering. Full model presented here accepting potential bias in comorbidity estimates. Complete case data. See table E5 for full models. Size of point estimate box proportional to population size. $\mathrm{Cl}$, confidence interval; IMD, index of multiple deprivation (centred and standardised).

A In-patient survival: ethnicity alone Ethnicity

$$
\begin{array}{r}
\text { White } \\
\text { South Asian } \\
\text { East Asian } \\
\text { Black } \\
\text { Other Ethnic Minority }
\end{array}
$$

B

In-patient survival: hierarchical baseline Ethnicity

White
South Asian
East Asian
Black
Ethnic Minority
$50-59$
$18-39$
$40-49$
$60-69$
$70-79$
$80+$
Male
Female

$$
\begin{array}{r}
1.19(1.05-1.36, p=0.008) \\
1.00(0.74-1.35, p=0.980) \\
1.05(0.91-1.21, p=0.500) \\
0.99(0.89-1.10, p=0.850) \\
0.30(0.23-0.40, p<0.001) \\
0.52(0.42-0.63, p<0.001) \\
2.06(1.84-2.31, p<0.001) \\
3.44(3.10-3.82, p<0.001) \\
4.97(4.49-5.50, p<0.001)
\end{array}
$$$$
0.76(0.72-0.79, p<0.001)
$$

Sex at Birth

$$
\text { Female }
$$
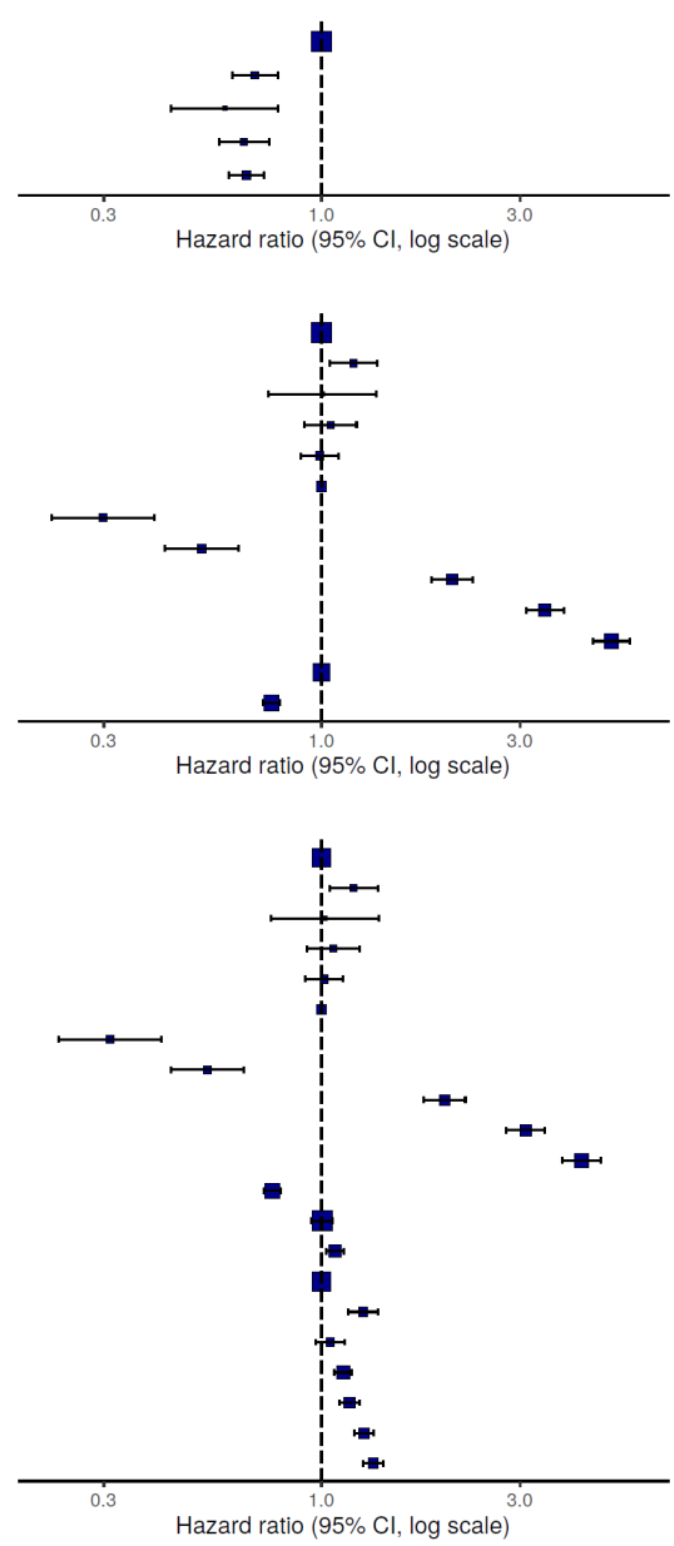
Figure 7. Mediation of apparent excess hazard of death in South Asian group by diabetes. (A) Three-way decomposition mediation analysis was performed for comorbidities associated with ethnicity (Figure 2; table E11 to E15) and outcome (Figure 7). All models included age and sex as covariates. The proportion of the total effect mediated by diabetes for mortality in South Asian patients with bootstrapped $95 \% \mathrm{Cl}$ intervals was determined. (B) Cox proportional hazards model of in-hospital mortality including age, sex, ethnicity, and diabetes status, including interactions between age, ethnicity, and diabetes. The cumulative probability of in-hospital death by day 30 after symptom onset was calculated for the subgroups shown and $95 \%$ confidence intervals determined by bootstrap resampling of models. See table E18 for full model.

A

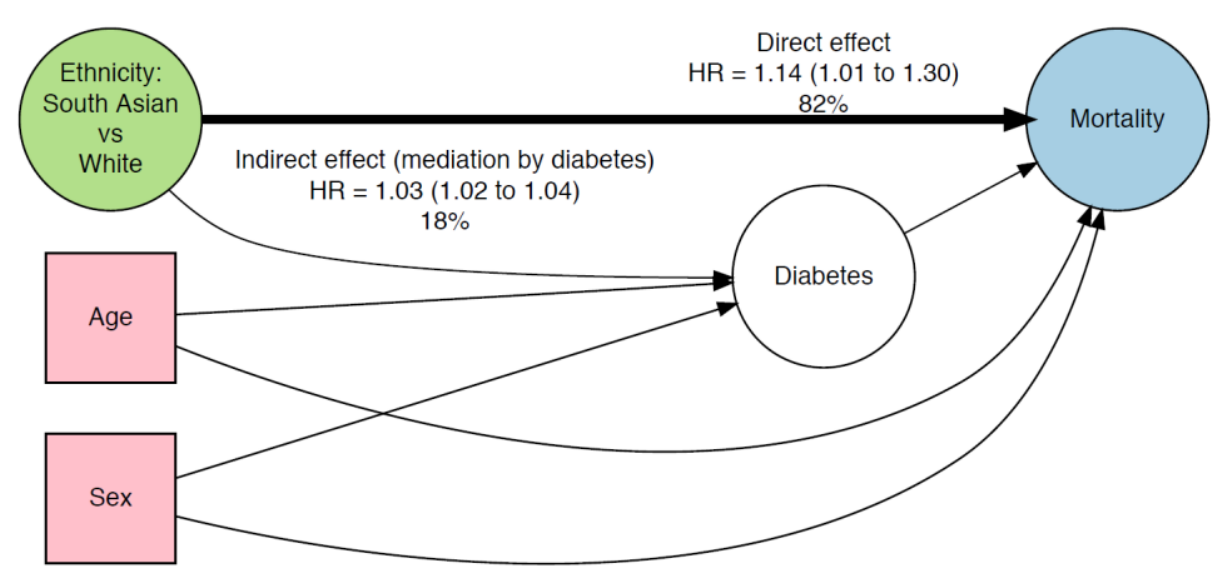

B

Ethnicity I Diabetes White I No White I Yes South Asian I No South Asian I Yes

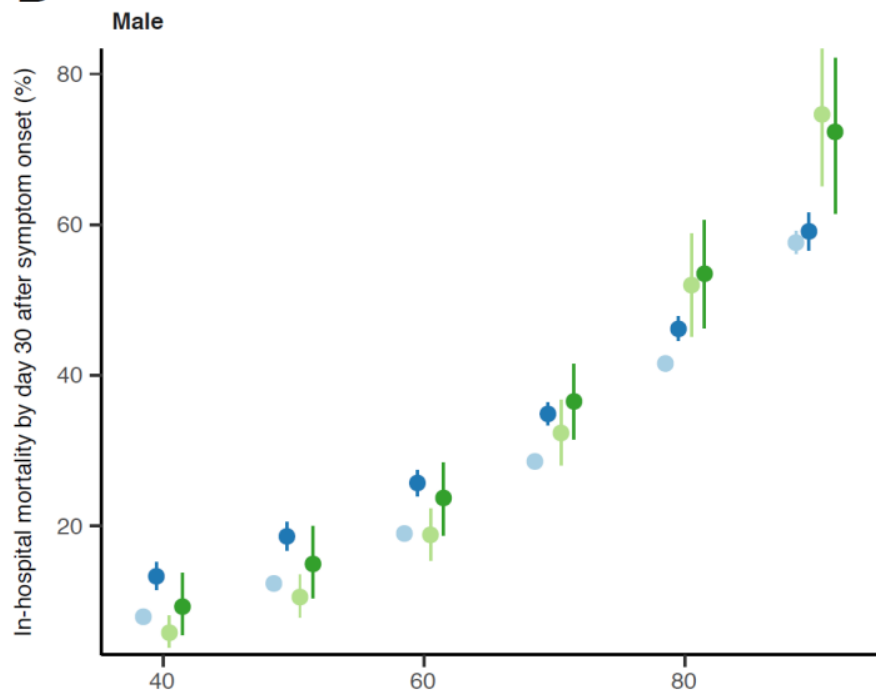

Female

Age (years) 


\section{End matter}

\section{Funding}

This work is supported by grants from: the National Institute for Health Research [award CO-CIN-01], the Medical Research Council [grant MC_PC_19059] and by the National Institute for Health Research Health Protection Research Unit (NIHR HPRU) in Emerging and Zoonotic Infections at University of Liverpool in partnership with Public Health England (PHE), in collaboration with Liverpool School of Tropical Medicine and the University of Oxford [NIHR award 200907], Wellcome Trust and Department for International Development [215091/Z/18/Z], and the Bill and Melinda Gates Foundation [OPP1209135], and Liverpool Experimental Cancer Medicine Centre for providing infrastructure support for this research (Grant Reference: C18616/A25153). JSN-V-T is seconded to the Department of Health and Social Care, England (DHSC). The views expressed are those of the authors and not necessarily those of the DHSC, DID, NIHR, MRC, Wellcome Trust or PHE.

\section{Ethical approval}

Ethical approval was given by the South Central - Oxford C Research Ethics Committee in England (Ref: 13/SC/0149), and by the Scotland A Research Ethics Committee (Ref: 20/SS/0028). The study was registered at https://www.isrctn.com/ISRCTN66726260.

\section{Contributions}

EM Harrison is guarantor and corresponding author for this work, and attests that all listed authors meet authorship criteria and that no others meeting the criteria have been omitted.

Conceptualisation: JK Baillie, J Dunning, G Carson, L Merson, JS Nguyen-Van-Tam, PJM Openshaw, MG Semple. Formal analysis: AB Docherty, C Gamble, EM Harrison, P Horby, L Norman, PJM Openshaw, R Pius, JM Read, MG Semple. Writing original draft: AB Docherty, PJM Openshaw, MG Semple. Writing reviewing and editing JK Baillie, AB Docherty, J Dunning, C Gamble, CA Green, EM Harrison, P Horby, JS Nguyen-VanTam, PJM Openshaw, MG Semple, L Sigfrid. Project administration: S Halpin, HE Hardwick, C Gamble, A Ho, KA Holden, J Lee, L Merson, D Plotkin, CD Russell. Investigation: EM Harrison, P Horby, C Gamble, CA Green, A Ho, MG Semple. Supervision: JK Baillie, HE Hardwick, EM Harrison, C Gamble, A Ho, P Horby, PJM Openshaw, MG Semple. Data curation: L Merson, S Halpin, C Jackson. Validation: KA Holden, S Halpin, C Jackson, Funding acquisition: JK Baillie, G Carson, P Horby, PJM Openshaw, MG Semple.

\section{Competing Interests}

All authors have completed the ICMJE uniform disclosure form at www.icmje.org/coi_disclosure.pdf and declare:

AB Docherty reports grants from Department of Health and Social Care, during the conduct of the study; grants from Wellcome Trust, outside the submitted work; CA Green reports grants from DHSC National Institute of Health Research UK, during the conduct of the study; PW Horby reports grants from Wellcome Trust / Department for International Development / Bill and Melinda Gates Foundation, grants from NIHR , during the conduct of the study; JS Nguyen-Van-Tam reports grants from Department of Health and Social Care, England, during the conduct of the study; and is seconded to the Department of Health and Social Care, England (DHSC); PJM Openshaw reports personal fees from consultancies and from European Respiratory Society; grants from MRC, MRC Global Challenge Research Fund, EU, NIHR Biomedical Research Centre, MRC/GSK, Wellcome Trust, NIHR (HPRU in Respiratory Infection), and NIHR Senior Investigator 
outside the submitted work. His role as President of the British Society for Immunology was unpaid but travel and accommodation at some meetings was provided by the Society. JK Baillie reports grants from Medical Research Council UK; MG Semple reports grants from DHSC National Institute of Health Research UK, grants from Medical Research Council UK, grants from Health Protection Research Unit in Emerging \& Zoonotic Infections, University of Liverpool, during the conduct of the study; other from Integrum Scientific LLC, Greensboro, NC, USA, outside the submitted work. EM Harrison, H Ardwick, J Dunning, R Pius, L Norman, KA Holden, JM Read, G Carson, L Merson, J Lee, D Plotkin, L Sigfrid, S Halpin, C Jackson, and C Gamble, all declare: no support from any organisation for the submitted work; no financial relationships with any organisations that might have an interest in the submitted work in the previous three years; and no other relationships or activities that could appear to have influenced the submitted work.

\section{Data sharing}

We welcome applications for data and material access via our Independent Data And Material Access Committee (https://isaric4c.net).

\section{Dissemination to participants and related patient and public communities}

ISARIC4C has a public facing website and twitter account @CCPUKstudy. We are engaging with print and internet press, television, radio, news, and documentary programme makers. We will explore distribution of findings with The Asthma UK and British Lung Foundation Partnership and take advice from NIHR Involve and GenerationR Alliance Young People's Advisory Groups.

\section{ISARIC Coronavirus Clinical Characterisation Consortium (ISARIC4C) Investigators}

Consortium Lead Investigator J Kenneth Baillie, Chief Investigator Malcolm G Semple. Co-Lead Investigator Peter JM Openshaw. ISARIC Clinical Coordinator Gail Carson. Co-Investigators: Beatrice Alex, Benjamin Bach, Wendy S Barclay, Debby Bogaert, Meera Chand, Graham S Cooke, Annemarie B Docherty, Jake Dunning, Ana da Silva Filipe, Tom Fletcher, Christopher A Green, Ewen M Harrison, Julian A Hiscox, Antonia Ying Wai Ho, Peter W Horby, Samreen ljaz, Saye Khoo, Paul Klenerman, Andrew Law, Wei Shen Lim, Alexander, J Mentzer, Laura Merson, Alison M Meynert, Mahdad Noursadeghi, Shona C Moore, Massimo Palmarini, William A Paxton, Georgios Pollakis, Nicholas Price, Andrew Rambaut, David L Robertson, Clark D Russell, Vanessa Sancho-Shimizu, Janet T Scott, Tom Solomon, Shiranee Sriskandan, David Stuart, Charlotte Summers, Richard S Tedder, Emma C Thomson, Ryan S Thwaites, Lance CW Turtle, Maria Zambon. Project Managers Hayley Hardwick, Chloe Donohue, Jane Ewins, Wilna Oosthuyzen, Fiona Griffiths. Data Analysts: Lisa Norman, Riinu Pius, Tom M Drake, Cameron J Fairfield, Stephen Knight, Kenneth A Mclean, Derek Murphy, Catherine A Shaw. Data and Information System Manager: Jo Dalton, Michelle Girvan, Egle Saviciute, Stephanie Roberts Janet Harrison, Laura Marsh, Marie Connor. Data integration and presentation: Gary Leeming, Andrew Law, Ross Hendry. Material Management: William Greenhalf, Victoria Shaw, Sarah McDonald. Local Principal Investigators: Kayode Adeniji, Daniel Agranoff, Ken Agwuh, Dhiraj Ail, Ana Alegria, Brian Angus, Abdul Ashish, Dougal Atkinson, Shahedal Bari, Gavin Barlow, Stella Barnass, Nicholas Barrett, Christopher Bassford, David Baxter, Michael Beadsworth, Jolanta Bernatoniene, John Berridge , Nicola Best, Pieter Bothma, David Brealey, Robin Brittain-Long, Naomi Bulteel, Tom Burden , Andrew Burtenshaw, Vikki Caruth, David Chadwick, Duncan Chambler, Nigel Chee, Jenny Child, Srikanth Chukkambotla, Tom Clark, Paul Collini , Graham Cooke, Catherine Cosgrove, Jason Cupitt, Maria-Teresa Cutino-Moguel, Paul Dark, Chris Dawson, Samir Dervisevic, Phil Donnison, Sam Douthwaite, Ingrid DuRand, Ahilanadan Dushianthan, Tristan Dyer, Cariad Evans, Chi Eziefula, Chrisopher Fegan, Adam Finn, Duncan Fullerton, Sanjeev Garg, Sanjeev Garg, Atul 
Garg, Jo Godden, Arthur Goldsmith, Clive Graham, Elaine Hardy, Stuart Hartshorn, Daniel Harvey, Peter Havalda, Daniel B Hawcutt, Maria Hobrok, Luke Hodgson, Anita Holme, Anil Hormis, Michael Jacobs, Susan Jain, Paul Jennings, Agilan Kaliappan, Vidya Kasipandian, Stephen Kegg, Michael Kelsey, Jason Kendall, Caroline Kerrison, Ian Kerslake, Oliver Koch, Gouri Koduri, George Koshy, Shondipon Laha, Susan Larkin, Tamas Leiner, Patrick Lillie, James Limb, Vanessa Linnett, Jeff Little, Michael MacMahon, Emily MacNaughton, Ravish Mankregod, Huw Masson, Elijah Matovu, Katherine McCullough, Ruth McEwen , Manjula Meda, Gary Mills , Jane Minton, Mariyam Mirfenderesky, Kavya Mohandas, James Moon, Elinoor Moore, Patrick Morgan, Craig Morris, Katherine Mortimore, Samuel Moses, Mbiye Mpenge, Rohinton Mulla, Michael Murphy, Megan Nagel, Thapas Nagarajan, Mark Nelson, Igor Otahal, Mark Pais, Selva Panchatsharam, Hassan Paraiso, Brij Patel, Justin Pepperell, Mark Peters, Mandeep Phull , Stefania Pintus, Jagtur Singh Pooni, Frank Post, David Price, Rachel Prout, Nikolas Rae, Henrik Reschreiter, Tim Reynolds, Neil Richardson, Mark Roberts, Devender Roberts, Alistair Rose, Guy Rousseau, Brendan Ryan, Taranprit Saluja, Aarti Shah, Prad Shanmuga, Anil Sharma, Anna Shawcross, Jeremy Sizer, Richard Smith, Catherine Snelson, Nick Spittle, Nikki Staines, Tom Stambach, Richard Stewart, Pradeep Subudhi, Tamas Szakmany, Kate Tatham, Jo Thomas, Chris Thompson, Robert Thompson, Ascanio Tridente, Darell Tupper - Carey, Mary Twagira, Andrew Ustianowski, Nick Vallotton, Lisa Vincent-Smith, Shico Visuvanathan , Alan Vuylsteke, Sam Waddy, Rachel Wake, Andrew Walden, Ingeborg Welters, Tony Whitehouse, Paul Whittaker, Ashley Whittington, Meme Wijesinghe, Martin Williams, Lawrence Wilson, Sarah Wilson, Stephen Winchester, Martin Wiselka, Adam Wolverson, Daniel G Wooton, Andrew Workman, Bryan Yates, Peter Young.

\section{Acknowledgements}

This work uses data provided by patients and collected by the NHS as part of their care and support \#DataSavesLives. We are extremely grateful to the 2,648 frontline NHS clinical and research staff and volunteer medical students, who collected this data in challenging circumstances; and the generosity of the participants and their families for their individual contributions in these difficult times. We also acknowledge the support of Jeremy J Farrar, Nahoko Shindo, Devika Dixit, Nipunie Rajapakse, Piero Olliaro, Lyndsey Castle, Martha Buckley, Debbie Malden, Katherine Newell, Kwame O'Neill, Emmanuelle Denis, Claire Petersen, Scott Mullaney, Sue MacFarlane, Chris Jones, Nicole Maziere, Katie Bullock, Emily Cass, William Reynolds, Milton Ashworth, Ben Catterall, Louise Cooper, Terry Foster, Paul Matthew Ridley, Anthony Evans, Catherine Hartley, Chris Dunn, D. Sales, Diane Latawiec, Erwan Trochu, Eve Wilcock, Innocent Gerald Asiimwe, Isabel Garcia-Dorival, J. Eunice Zhang, Jack Pilgrim, Jane A Armstrong, Jordan J. Clark, Jordan Thomas, Katharine King, Katie Alexandra Ahmed, Krishanthi S Subramaniam , Lauren Lett, Laurence McEvoy, Libby van Tonder, Lucia Alicia Livoti, Nahida S Miah, Rebecca K. Shears, Rebecca Louise Jensen, Rebekah Penrice-Randal, Robyn Kiy, Samantha Leanne Barlow, Shadia Khandaker, Soeren Metelmann, Tessa Prince, Trevor R Jones, Benjamin Brennan, Agnieska Szemiel, Siddharth Bakshi, Daniella Lefteri, Maria Mancini, Julien Martinez, Angela Elliott, Joyce Mitchell, John McLauchlan, Aislynn Taggart, Oslem Dincarslan, Annette Lake. 
Click here to access/download Supplementary Material Ethnicity_online_supplement.docx 


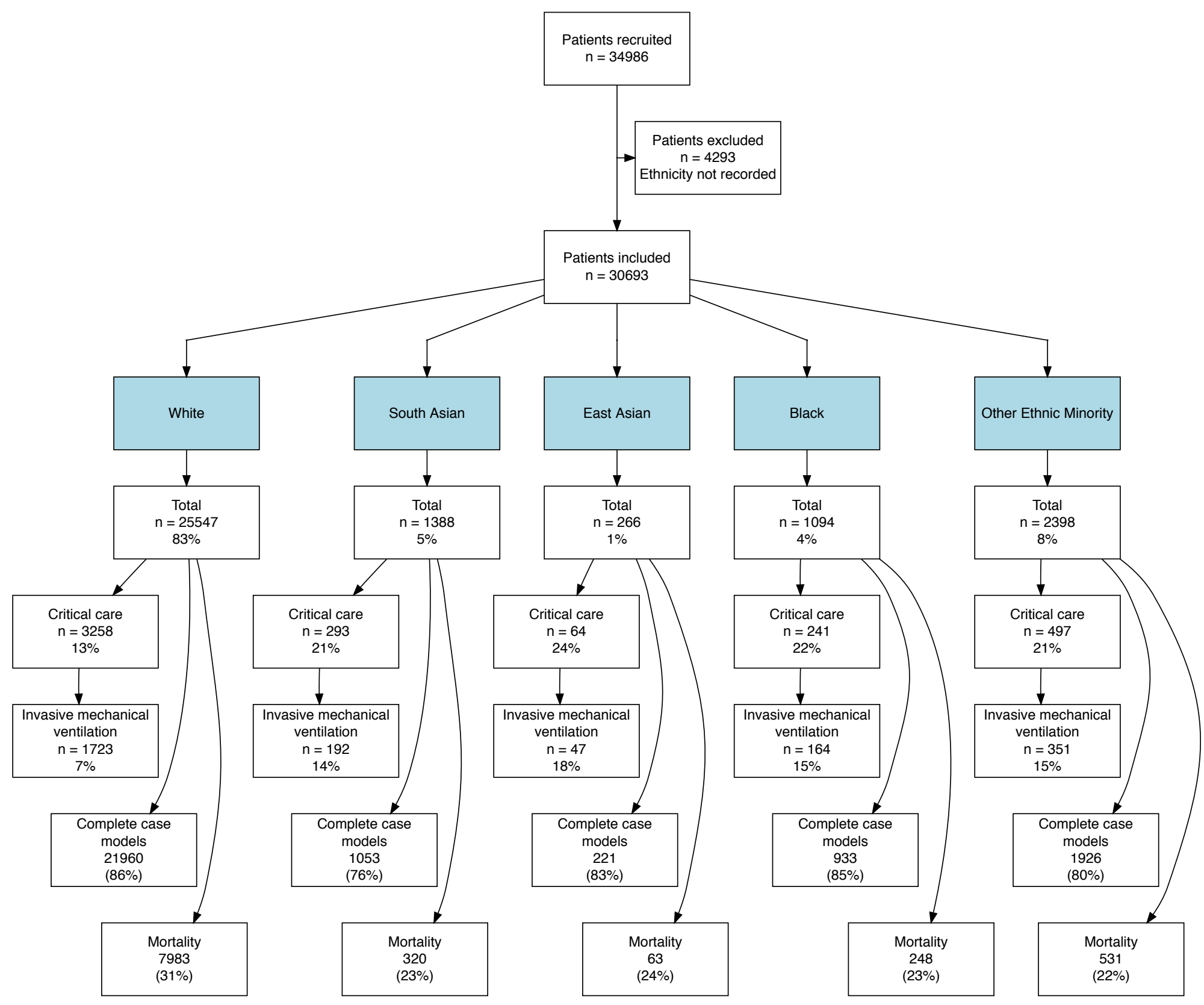


B Obesity

Ethnicity

White

South Asian

East Asian

Black

Other Ethnic Minority

\section{Chronic cardiac disease}

Ethnicity

White

South Asian

East Asian

Black

Other Ethnic Minority

\section{Chronic pulmonary disease}

Ethnicity

White

South Asian

East Asian

Black

Other Ethnic Minority

\section{E Chronic kidney disease \\ Ethnicity}

White

South Asian

East Asian

Black

Other Ethnic Minority

\section{Dementia}

Ethnicity

White

South Asian

East Asian

Black

Other Ethnic Minority
$0.76(0.64-0.90, p=0.002)$

$0.57(0.38-0.86, p=0.007)$

$1.04(0.87-1.25, p=0.664)$

$0.83(0.73-0.95, p=0.008)$

$1.03(0.87-1.22, p=0.717)$

$0.81(0.55-1.17, p=0.260)$

$0.60(0.49-0.73, p<0.001)$

$0.74(0.65-0.84, p<0.001)$

$0.49(0.39-0.63, p<0.001)$

$0.44(0.26-0.77, p=0.004)$

$0.45(0.34-0.59, p<0.001)$

$0.62(0.53-0.73, p<0.001)$

$1.66(1.38-2.00, p<0.001)$

0.87 (0.54-1.40, $p=0.557)$

$1.59(1.30-1.93, p<0.001)$

$0.88(0.76-1.04, p=0.127)$

$0.62(0.46-0.83, \mathrm{p}=0.001)$

$0.99(0.57-1.71, p=0.976)$

$0.63(0.47-0.85, p=0.002)$

$0.80(0.67-0.97, p=0.020)$
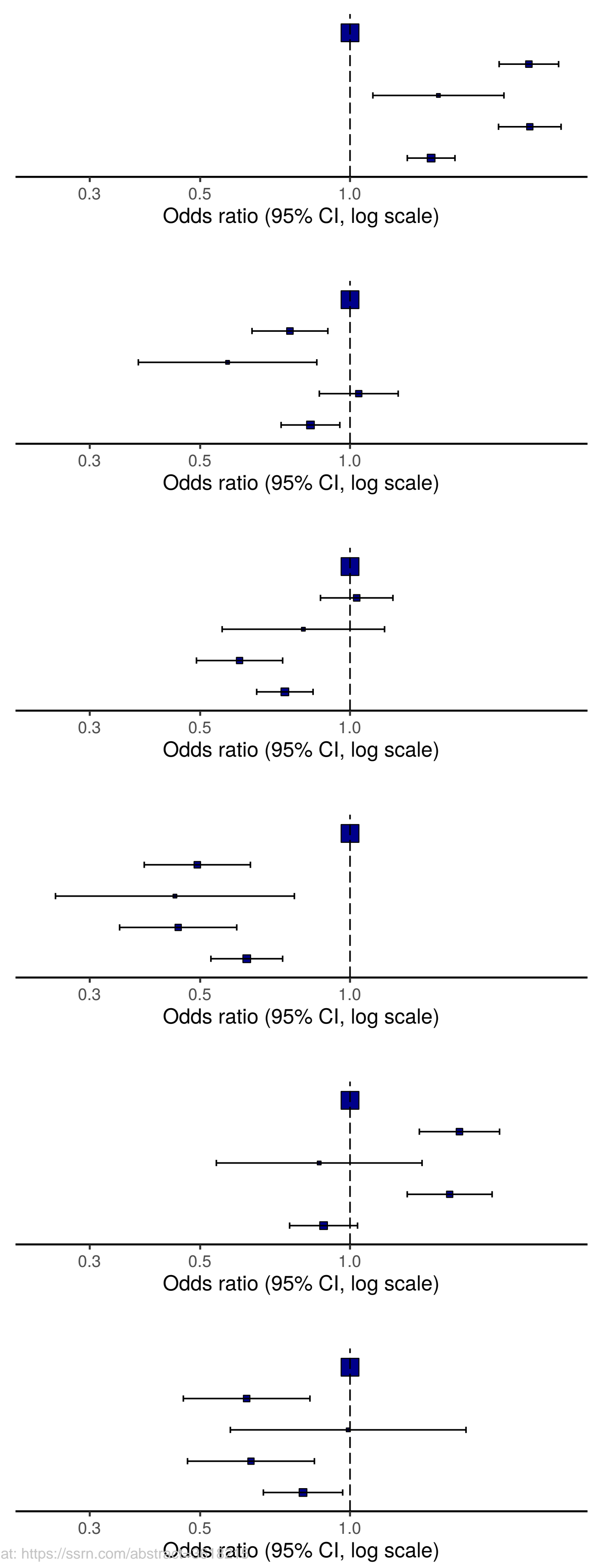


\section{A Severity score (NEWS2) on admission}

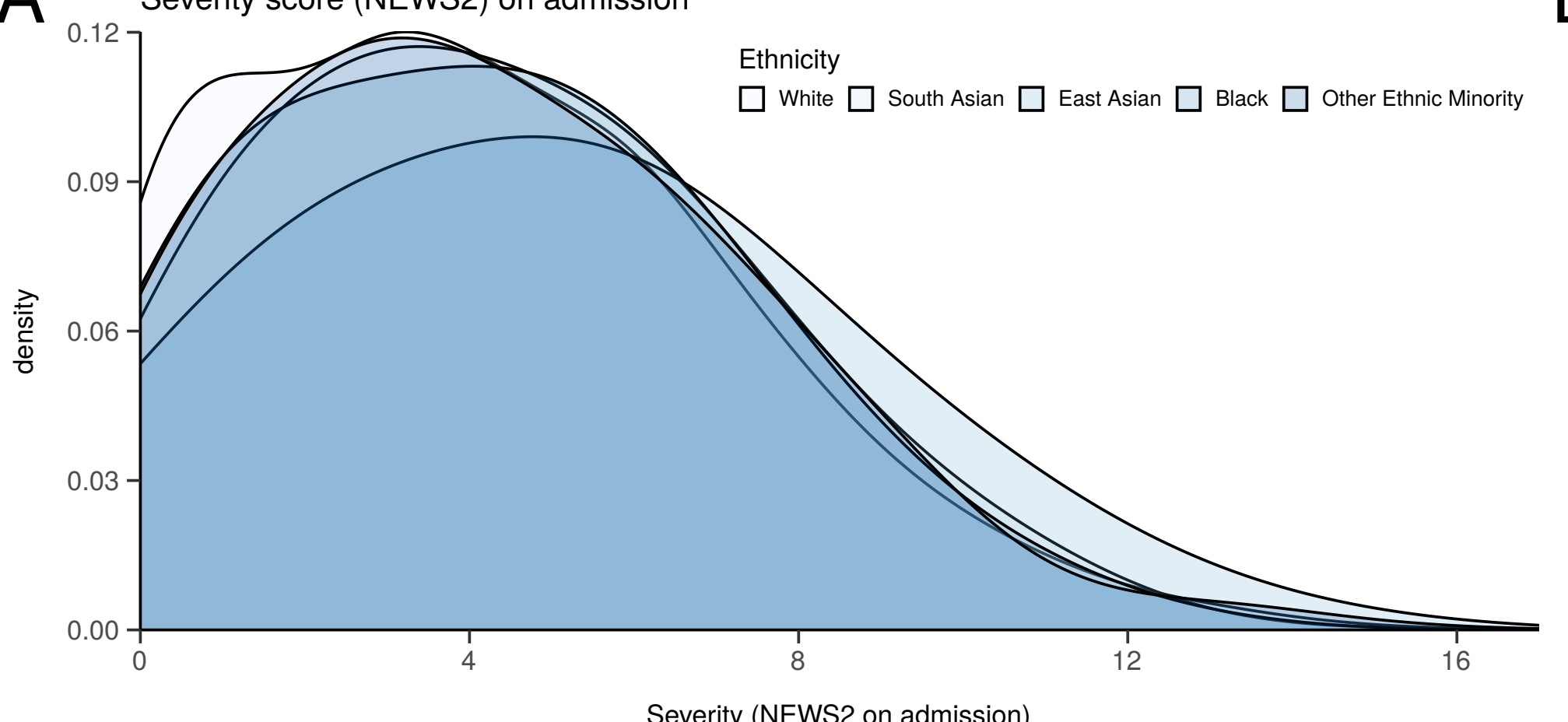

Severity (NEWS2 on admission)

C Patients with NEWS2 score $>2$ on admission to hospital with COVID-19 Proportions with binomial confidence intervals

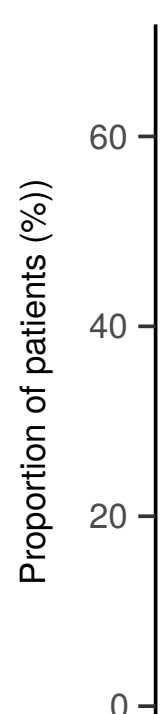

$11727 / 21610$ $(54 \%)$

White
$585 / 1033$

$(57 \%)$

South Asian

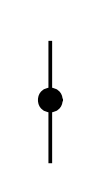

$133 / 214$

$(62 \%)$

East' Asian

Ethnicitity
B Time from symptom onset to admission

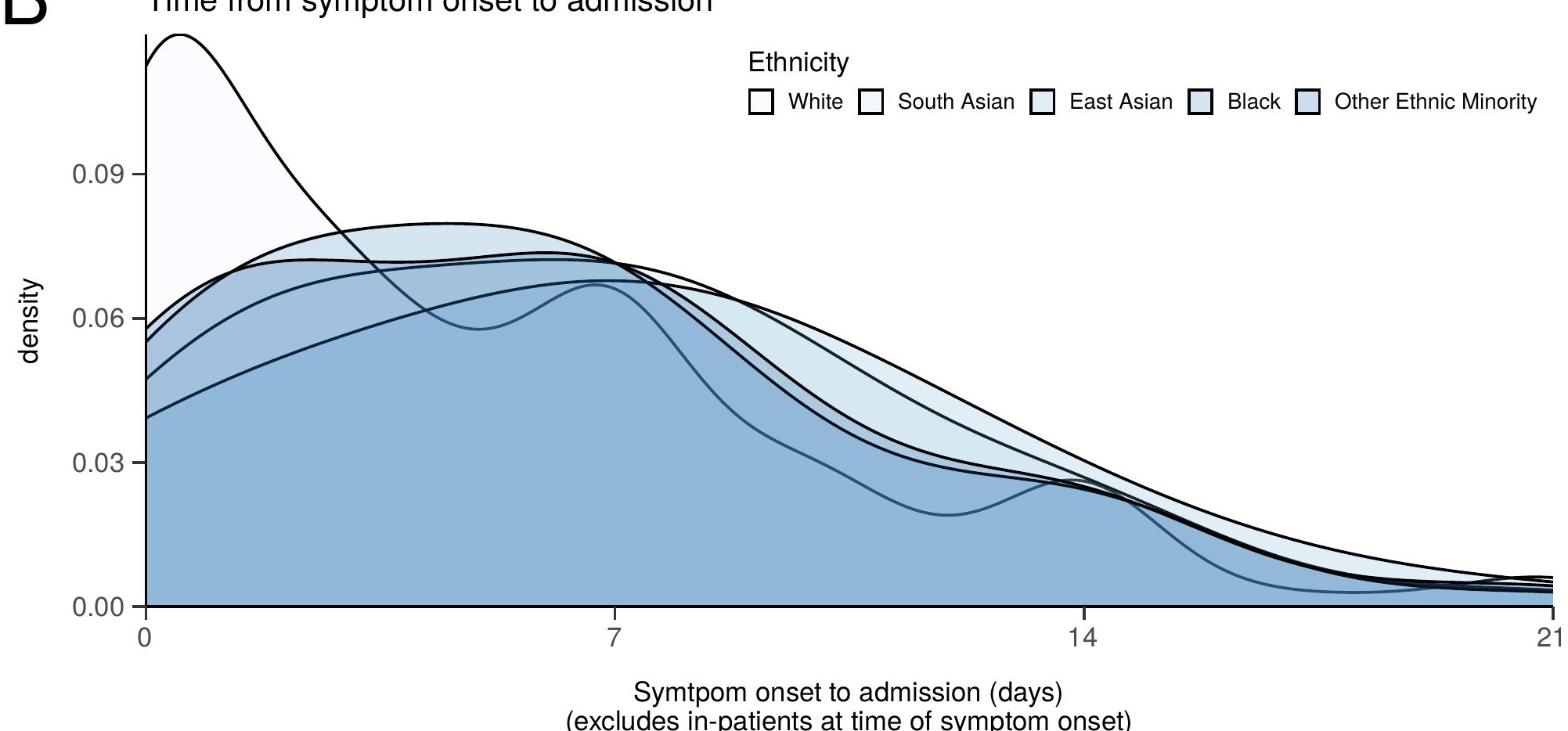

D Time to admission: hazard ratio ( $95 \%$ confidence interval)
Ethnicity
White

\section{South Asian $\quad 0.90(0.68-1.20, p=0.487)$ \\ East Asian $\quad 1.16(0.68-1.97, \mathrm{p}=0.583)$ \\ Black $1.10(0.83-1.44, p=0.516)$}

Other Ethnic Minority $\quad 0.87(0.71-1.07, p=0.185)$

$1054 / 1897$

$(57 \%) \quad(56 \%)$

Black Other Ethnic Minority

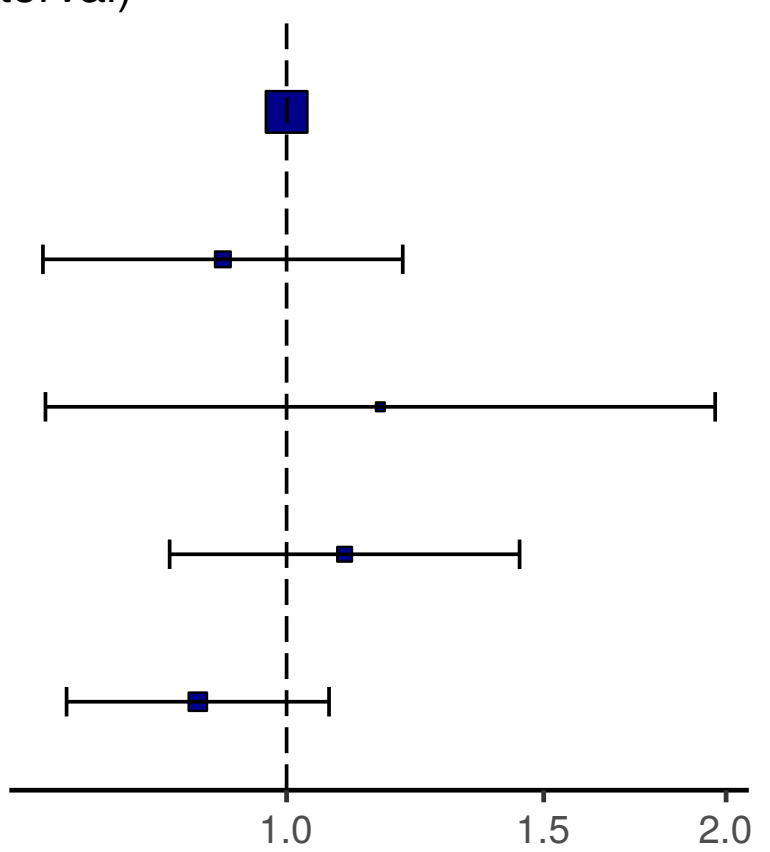

Hazard ratio $(95 \% \mathrm{Cl}$, log scale) 
A Critical care admission in hospitalised patients with COVID-19 Unadjusted proportions with binomial confidence intervals
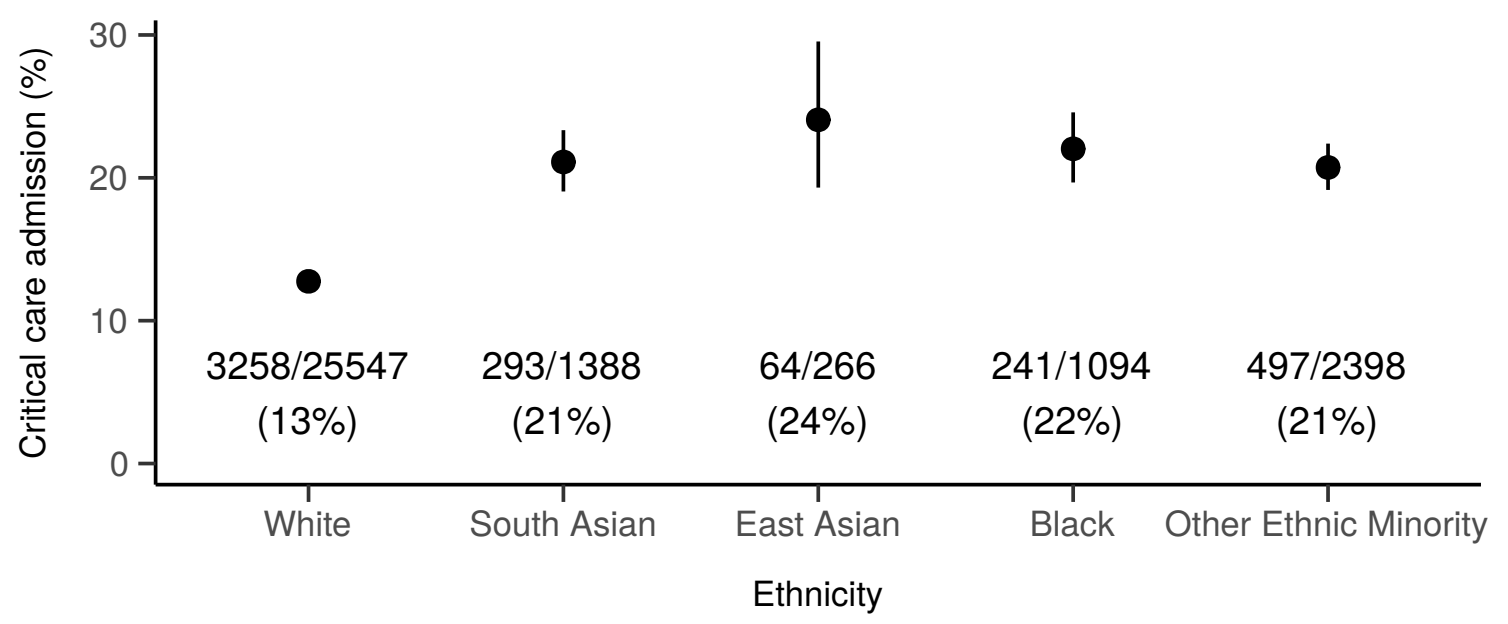

C Case fatality in patients with $>2$ weeks follow-up Unadjusted proportions with binomial confidence intervals

כ)

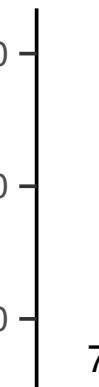

$248 / 1094$

$531 / 2398$

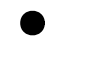

$7983 / 25547$

(31\%)

White

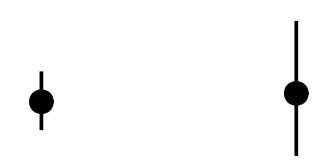

$320 / 1388$

$(23 \%)$

South Asian
$63 / 266$

(24\%)

(23\%)

$(22 \%)$

B Unadjusted proportions with binomial confidence intervals

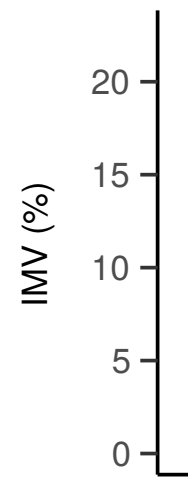
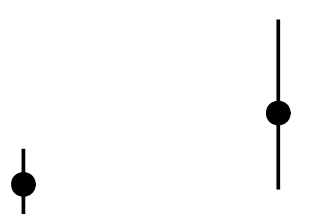

$1723 / 25547$

$192 / 1388$

$47 / 266$

$164 / 1094$

$351 / 2398$

(7\%)

$(14 \%)$

$(18 \%)$

$(15 \%)$

$(15 \%)$

White

South Asian

East Asian

Black

Other Ethnic Minority

Ethnicity

D Case fatality in patients with $>30$ days follow-up

Unadjusted proportions with binomial confidence intervals

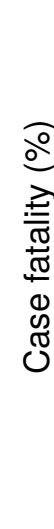

o
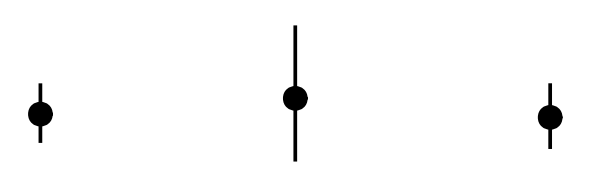

$7389 / 22723$

$300 / 1268$

$62 / 249$

$242 / 1034$

$504 / 2191$

(33\%)

$(24 \%)$

(25\%)

South Asian

East Asian

Ethnicief 
A Critical care admission: ethnicity alone

Ethnicity

White

South Asian

East Asian

Black

Other Ethnic Minority

B

\section{Ethnicity}

White

South Asian

East Asian

Black

Other Ethnic Minority

Age on admission (years)

50-59

18-39

$40-49$

60-69

70-79

$80+$

Sex at Birth

Female
2.07 (1.78-2.39, $\mathrm{p}<0.001)$

$2.16(1.57-2.91, p<0.001)$

$1.96(1.67-2.29, p<0.001)$

$1.82(1.62-2.04, p<0.001)$
$1.28(1.09-1.52, \mathrm{p}=0.003)$

$1.29(0.92-1.79, p=0.136)$

$1.36(1.14-1.62, p=0.001)$

$1.29(1.13-1.47, p<0.001)$

$0.58(0.50-0.68, p<0.001)$

$0.89(0.78-1.01, p=0.080)$

$0.84(0.75-0.93, p=0.001)$

$0.39(0.35-0.44, p<0.001)$

$0.09(0.08-0.10, p<0.001)$

$0.59(0.55-0.64, p<0.001)$

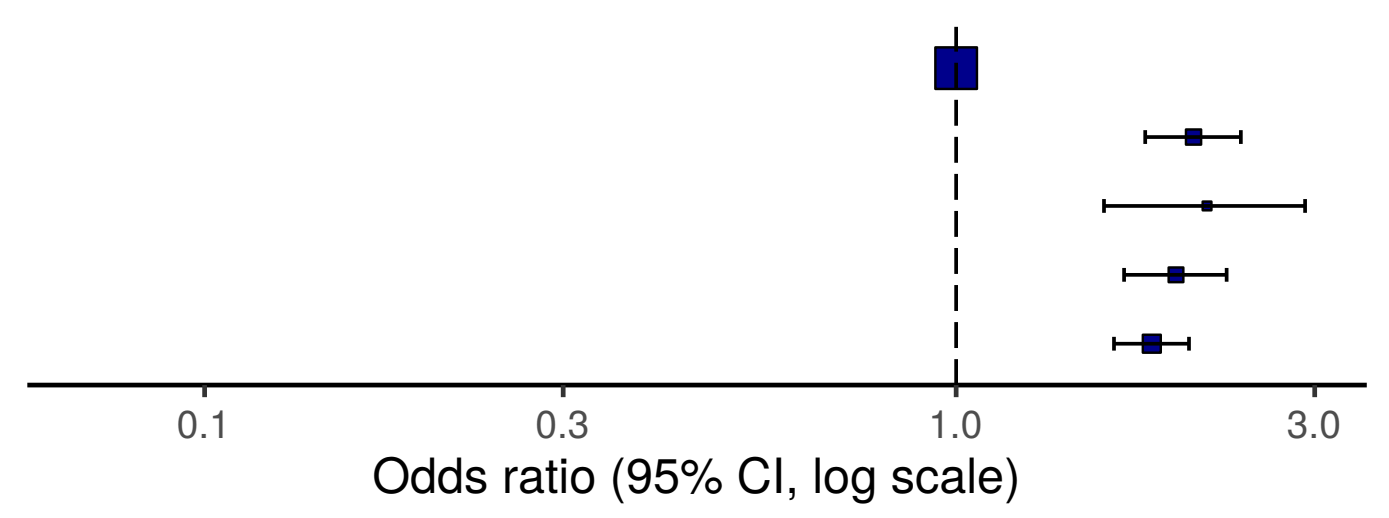

C

Critical care: hierarchical with potential mediators

Ethnicity

White

South Asian

East Asian

Black

Other Ethnic Minority

Age on admission (years)

50-59

18-39

$40-49$

$60-69$

$70-79$

$80+$

Sex at Birth

Female

Deprivation (IMD)

Diabetes

Obesity

Chronic cardiac disease

Chronic pulmonary disease

Chronic kidney disease

Dementia

$1.32(1.12-1.56, p=0.001)$

$1.30(0.93-1.81, p=0.127)$

$1.34(1.12-1.61, \mathrm{p}=0.001)$

$1.26(1.10-1.44, p=0.001)$

$0.55(0.47-0.64, p<0.001)$

$0.86(0.75-0.98, p=0.026)$

$0.95(0.86-1.06, p=0.378)$

$0.56(0.50-0.62, p<0.001)$

$0.16(0.14-0.19, p<0.001)$

$0.56(0.52-0.61, p<0.001)$

$1.03(0.76-1.39, p=0.873)$

$1.00(0.92-1.09, p=0.969)$

$1.79(1.61-2.00, \mathrm{p}<0.001)$

$1.07(0.92-1.24, p=0.373)$

$0.64(0.57-0.71, p<0.001)$

$0.71(0.63-0.80, p<0.001)$

$0.66(0.57-0.75, p<0.001)$

$0.26(0.21-0.33, p<0.001)$
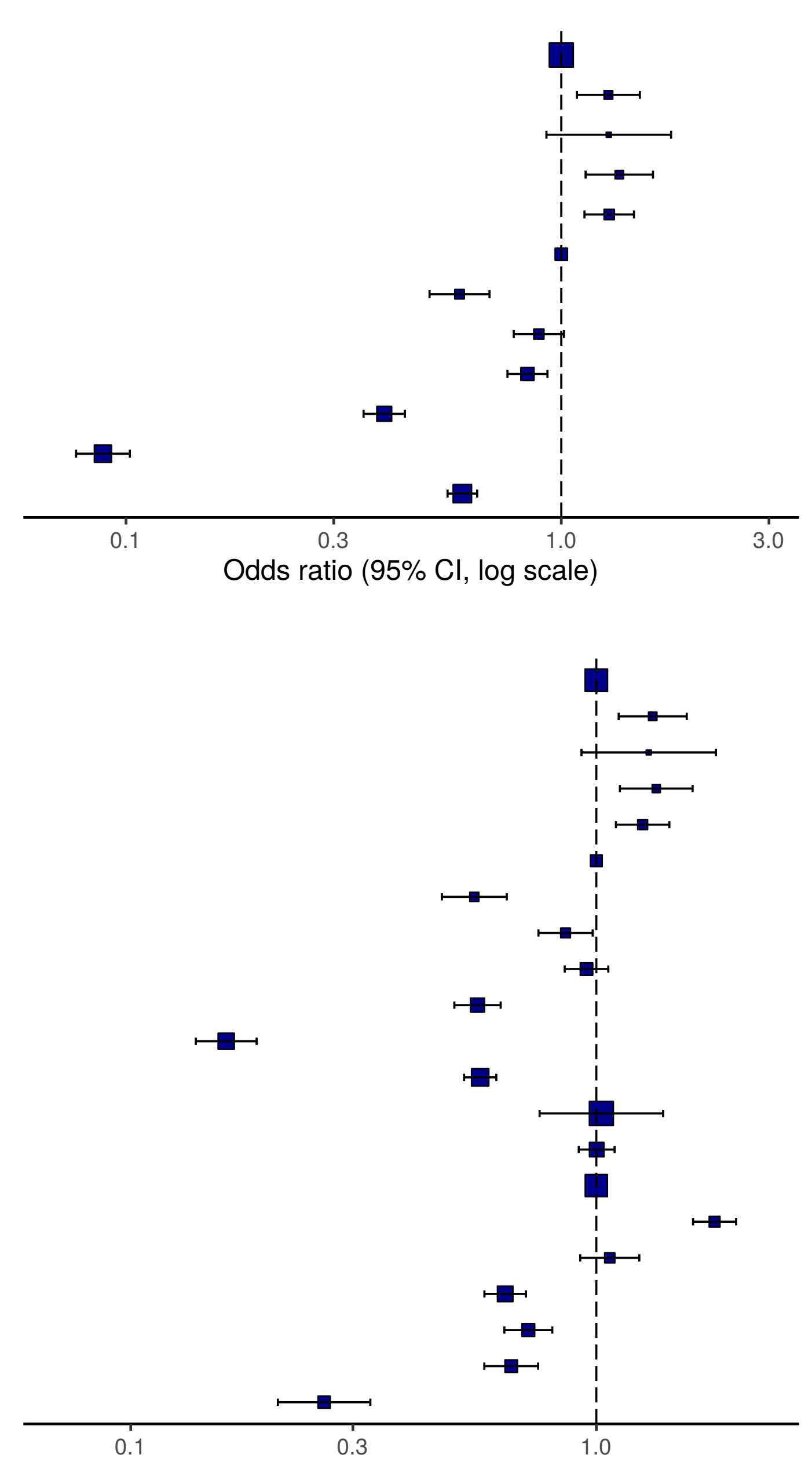

Ddds ratio (95\% Cl, log scale) 
A In-patient survival: ethnicity alone Ethnicity

White

South Asian

East Asian

Black

Other Ethnic Minority

In-patient survival: hierarchical baseline

Ethnicity

White

South Asian

East Asian

Black

Other Ethnic Minority

Age on admission (years)

50-59

18-39

$40-49$

60-69

$70-79$

$80+$

Sex at Birth

Male

Female

$0.69(0.61-0.79, \mathrm{p}<0.001)$

$0.59(0.44-0.79, p<0.001)$

$0.65(0.57-0.75, p<0.001)$

$0.66(0.60-0.73, p<0.001)$

$1.19(1.05-1.36, p=0.008)$

$1.00(0.74-1.35, p=0.980)$

$1.05(0.91-1.21, p=0.500)$

$0.99(0.89-1.10, p=0.850)$

$0.30(0.23-0.40, p<0.001)$

$0.52(0.42-0.63, p<0.001)$

$2.06(1.84-2.31, p<0.001)$

$3.44(3.10-3.82, p<0.001)$

$4.97(4.49-5.50, p<0.001)$

$0.76(0.72-0.79, p<0.001)$

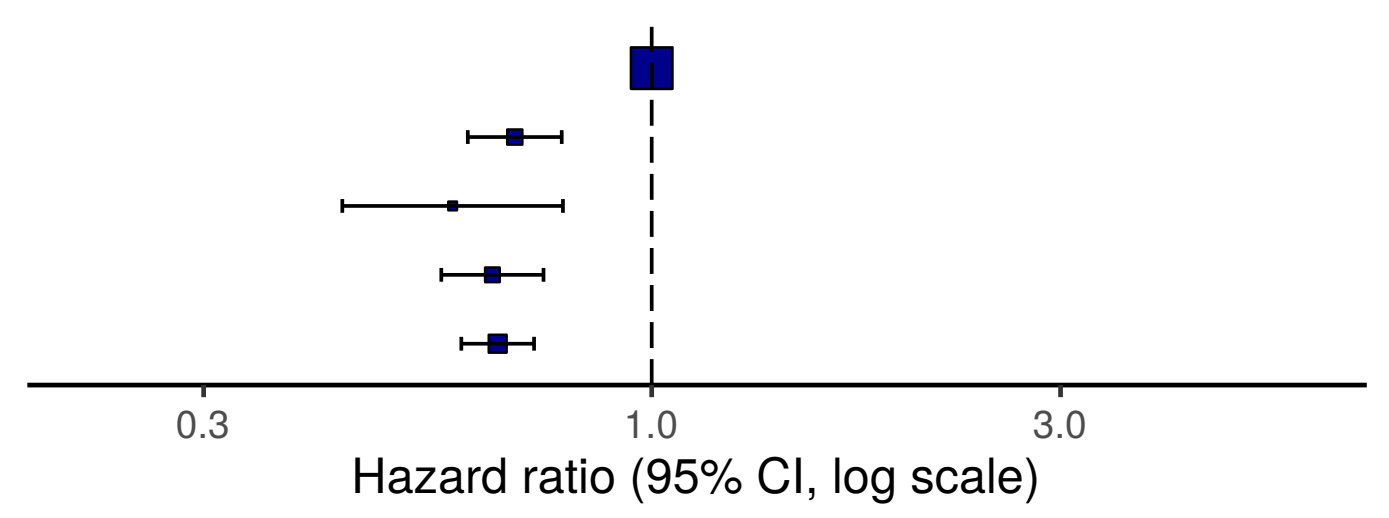

C

In-patient survival: hierarchical with potential mediators

Ethnicity

White

South Asian

East Asian

Black

Other Ethnic Minority

Age on admission (years)

50-59

18-39

$40-49$

60-69

$70-79$

$80+$

Sex at Birth

Female

Deprivation (IMD)

Diabetes

Obesity

Chronic cardiac disease

Chronic pulmonary disease

Chronic kidney disease

Dementia

$1.20(1.05-1.36, p=0.008)$

$1.02(0.76-1.38, p=0.890)$

$1.07(0.92-1.23, p=0.380)$

$1.01(0.91-1.12, p=0.790)$

$0.31(0.23-0.41, p<0.001)$

$0.53(0.43-0.65, p<0.001)$

1.98 (1.76-2.22, $p<0.001)$

$3.09(2.78-3.44, p<0.001)$

4.21 (3.79-4.68, $p<0.001)$

$0.76(0.73-0.80, p<0.001)$

$1.00(0.95-1.06, p=0.890)$

$1.08(1.03-1.13, p=0.003)$

$1.26(1.16-1.37, p<0.001)$

$1.05(0.97-1.14, p=0.240)$

$1.13(1.08-1.18, p<0.001)$

$1.17(1.11-1.23, p<0.001)$

$1.26(1.20-1.34, p<0.001)$

$1.33(1.26-1.41, p<0.001)$
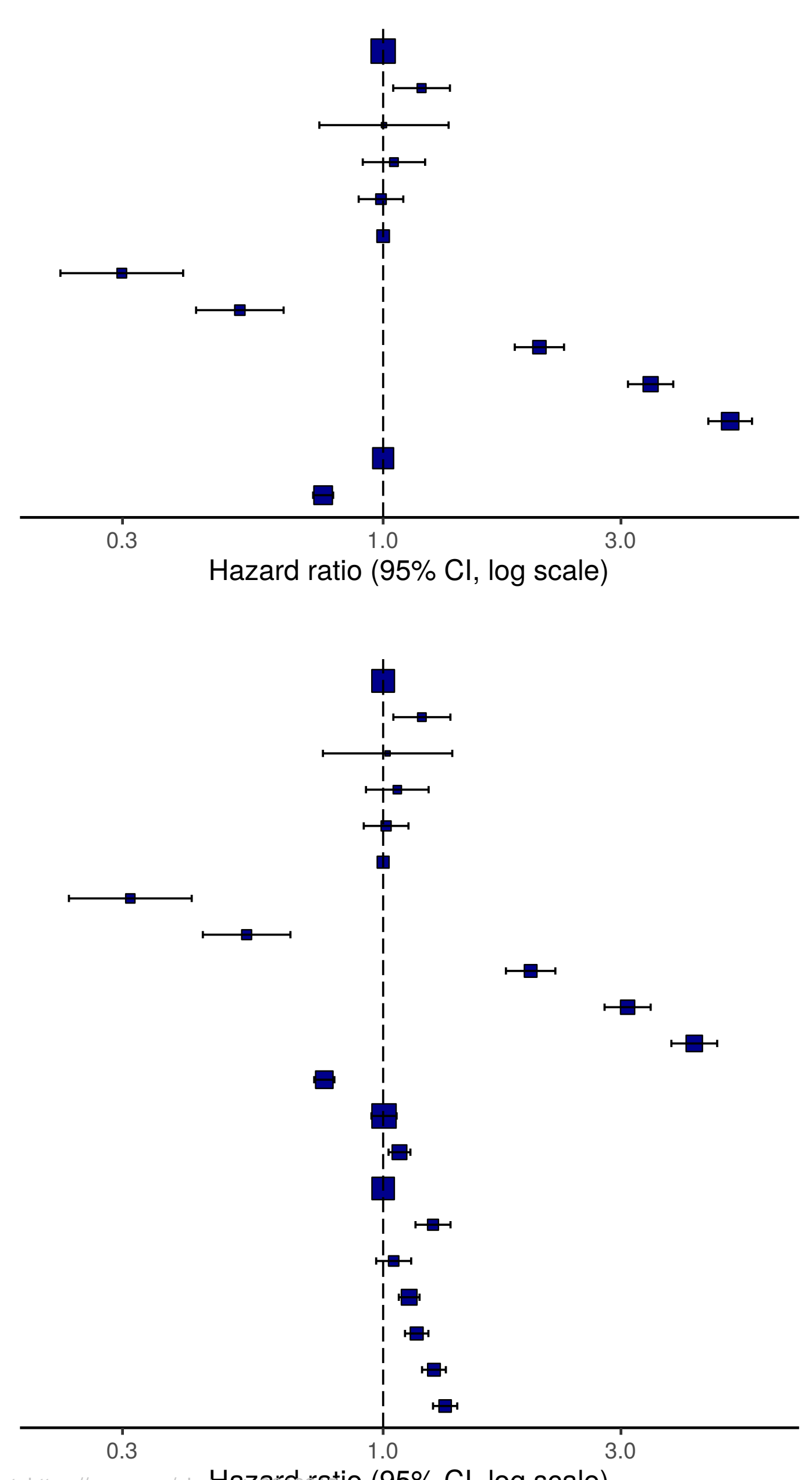

Hazardratio $(95 \% \mathrm{Cl}$, log scale) 
A

B

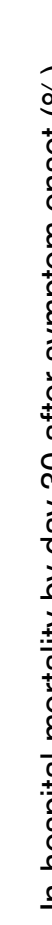

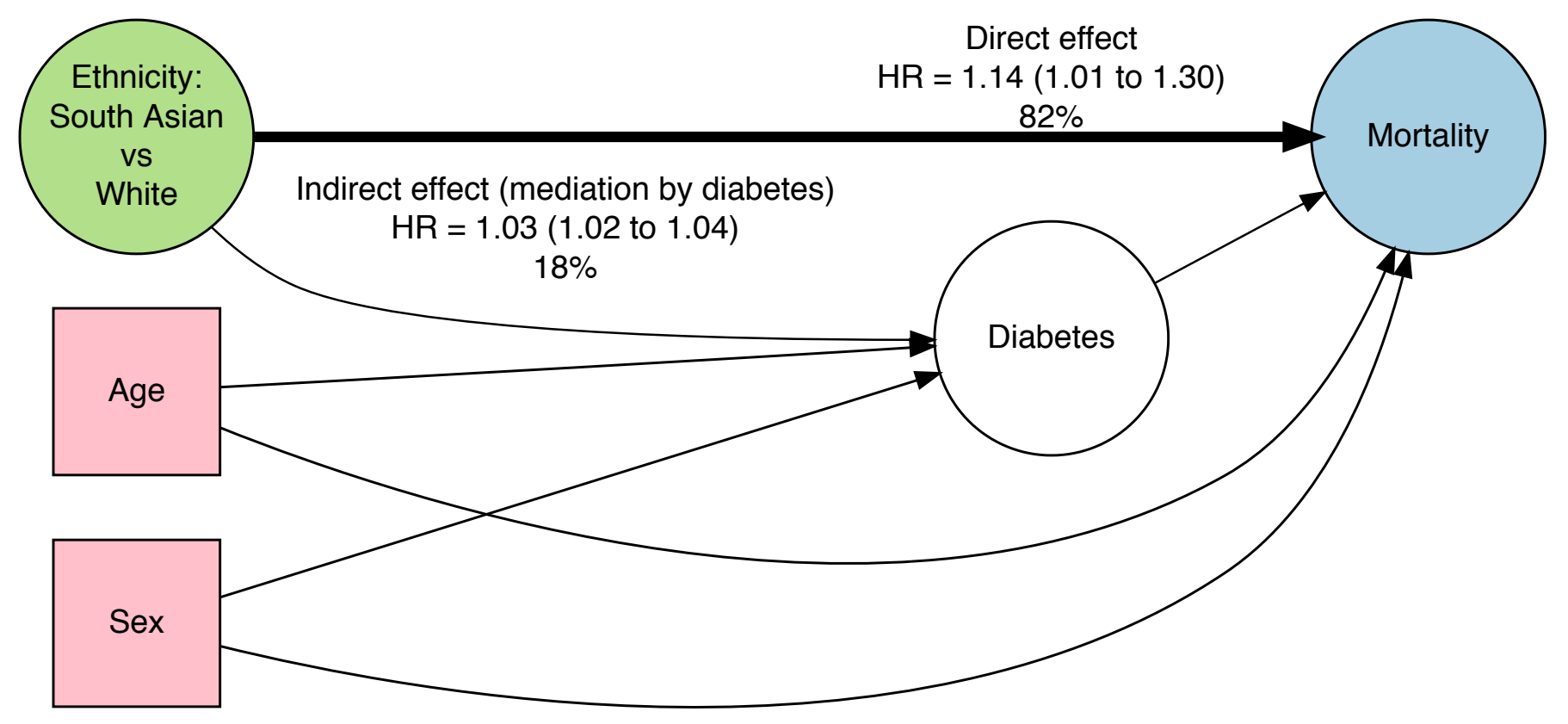

Ethnicity I Diabetes

White I No

White I Yes

South Asian I No

South Asian I Yes

Male

\section{Female}

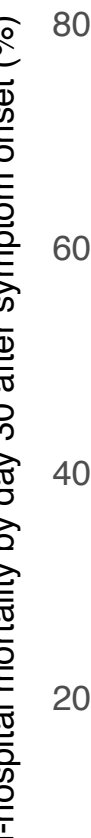

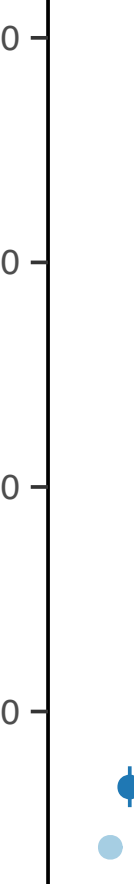

40

60
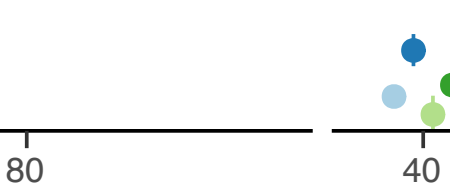

This preprint research paper has not been peer reviewed. Figel(yearsi) py available at: https://ssrn.com/abstract=3618215 